\title{
The use of transient electrolysis in the technology of oxide composite nanostructured materials: review
}

\author{
Zh. I. Bespalova, A. V. Khramenkova \\ Platov South-Russia State Polytechnical University (NPI), Novocherkassk, Russia \\ anna.v17@yandex.ru
}

PACS 81.15.-Z

DOI 10.17586/2220-8054-2016-7-3-433-450

\begin{abstract}
The available experimental material relating to the patterns of formation and properties of functional nanostructured transition metal oxide (Mo, $\mathrm{Co}, \mathrm{Mn}, \mathrm{Ni}, \mathrm{Fe}, \mathrm{V}$ ) composite materials is reviewed. Advanced coatings are considered those whose formation method are simple and do not require high energy costs, expensive equipment and permit the creation of materials with desired physical and chemical properties in a specified manner. In this review, the priority of oxide composite nanostructured materials technology is given to a transient electrolysis method based on the analysis of a data set that demonstrates its advantages. The results are presented for a number of studies aimed at identifying and analyzing the nature and regularities of processes that take place when obtaining oxide composite nanostructured materials using transient electrolysis methods.
\end{abstract}

Keywords: asymmetric alternating current, composite oxide nanostructured coatings, optically selective coatings, catalytically active oxide composite coatings, metal oxides, electrolyte, solution, asymmetry parameter.

Received: 9 December 2015

\section{Introduction}

The research related to the enhancement of existing technologies for producing coatings and their simplification is aimed primarily at finding the most cost-efficient procedures.

Transient electrolysis, which uses periodically alternating (symmetric, asymmetric and pulsed) currents, should be referred to in such discussions. There are several data that point out the advantages for the deposition of coatings using an asymmetrical alternating current [1-3]. The successful use of current without previous rectification is undoubtedly worthwhile. The appropriate alternating current enables the deposition of coatings at lower temperatures, making the process more energy-efficient because of the possibility of using lower voltages. This increases the rate of electrolysis and, respectively, the process productivity, allowing one to change the physical and chemical properties of coatings by varying a wide range of electrolysis parameters (current density, composition and concentration of electrolyte components), and to obtain more dense and fine coatings as well as to increase the upper limit of working current density and to reduce internal stress in a coating, i.e. allows coating property regulation by a purely electrical method. Coatings that are obtained using an alternating polarity current differ from those obtained by a direct current method in microstructure, porosity, surface purity and mechanical properties.

Transient regimes, however, are considered worse as compared to conventional ones and consequently, are used much more rarely.

This is explained by the fact that transient processes are considerably more complicated than stationary ones, because both cathodic and anodic electrode reactions proceed under the periodic changes of an electrical flow and then transient processes occur.

To date, in the area of transient electrolysis, much research has been done [4-12], many factors which affect these processes have been discovered. All this gives one reason to consider it worthwhile to use an asymmetrical current in electrochemical productions.

Accumulated experimental data [13-17] show that in many cases transient electrolysis allows one to achieve effects that either cannot be achieved using a direct current or can be achieved in a much more complicated fashion. The ability to affect an electrochemical process more efficiently and flexibly due to the change of a mode and frequency variation of amplitudes for both anodic and cathodic current pulses is an undeniable advantage for transient electrolysis.

Electrochemical synthesis using a line-frequency alternating current allows one to obtain a number of metal oxides [18-21]. When using an alternating current, Dolinina et al. [22] obtained a copper-cadmium oxide system in a solution of a sodium hydroxide, and determined that in the presence of copper, the rate of cadmium oxidation rose 2- to 3-fold. Thus, predicting the operating parameters of copper electrolysis, one can obtain cadmium oxide systems of a prescribed composition. The asymmetric alternating current was successfully applied to obtain films 
of barium titanate $\left(\mathrm{BaTiO}_{3}\right)$ from an aqueous suspension in the presence of 0.5 mass \% polyvinyl alcohol using an electrophoresis method [23].

Under the influence of an alternating current, Jagminas et al. [24] precipitated bismuth oxide in the pores of aluminium, the size of its particles being $5-100 \mathrm{~nm}$. The high-frequency alternating current allowed the impregnation of a nanostructured cadmium selenide (CdSe) in anodic aluminum oxide pores [25]. The development of such nanocomposite materials, including metamaterials [26] is very promising for applications in electronic, optical and magnetic devices [26,27]. Nano-scale particles of a cerium oxide $\left(\mathrm{CeO}_{2}\right)$ were obtained [28] from $0.1 \mathrm{M} \mathrm{Ce}\left(\mathrm{NO}_{3}\right)_{2}$ aqueous solution under polarization using an alternating current on the surface of a platinum electrode, the size of a particle being regulated by electrolysis conditions ( $\mathrm{pH}$ and component electrolyte composition, temperature, current density), which set this method apart from other precipitation [29,30], pyrolysis [31], hydrothermal [32-36] and sonochemical [37-39] synthetic methods. Nanostructured coatings based on titanium oxide were obtained as a result of electrophoretic deposition under the influence of an asymmetrical alternating current [16]. This method also has a number of advantages compared to other widely-used nanocrystal titanium dioxide methods [40-45]. It should be noted that the use of an asymmetric alternating current for these purposes allowed suppression of gas bubble formation due to the absence of electrolysis of water on electrodes, and obviated the need for using organic stabilizers in the electrolyte-suspension. The electrophoretic coatings using an asymmetric alternating current thus was shown to be favorable both environmentally and economically.

Because the use of an alternating current suggests a whole number of electrode reactions and the change of electrode capacity occurs under conditions which are far from an equilibrium state, the formation of metal oxide products having different degrees of oxidation with defective structure are predetermined. The cyclicity of the polarizing voltage leads to two consecutive processes on the surface of an electrode: the first one is the formation of oxide phases in an anodic current half-cycle, and the second one is the discharge of protons, hydrogen being emitted in a cathodic current half-cycle. Thus, the alternating current allows one to influence the most important property of oxide films, i.e. their porosity.

To obtain composite materials on the basis of metal oxides deposited from aqueous solutions of their salts under polarization using an asymmetric alternating current is equally promising, but still somewhat unexplored. The formation of such composite materials relates to the area of nanotechnologies and nanomaterials because the substance of a matrix of a composite material is finely dispersed. Such systems, compared with similar monolithic objects, have specific and in some cases unique physical and chemical properties.

In recent years there has been increased interest in composite materials based on polymer matrix with nanosized metal oxide particles [46-53]. This is due to their wide application ranging from membranes, catalysts to constructive materials and materials that are used in information technology. So, methods of synthesis of nanoparticles and nanostructures play an important role while determining their quality characteristics. Among the methods for nanoparticle and nanostructure synthesis, [54-71] electrochemical methods have not been thoroughly explored. At the same time, the use of electrochemical methods to obtain nanoparticles and nanostructured materials is very attractive, as they do not require complex equipment, they are easy and economical compared to other methods, and in some cases they allow one to obtain oxide films of specified morphology and composition by controlling the composition of electrolyte and electrolysis modes.

The transient electrolysis allows the formation of coatings which differ in their properties from similar ones that are formed using a direct current due to the cycling of surface layers, irreversibility of electrode reactions of oxidation and reduction.

This method gives tremendous opportunities to control electrode processes by current modes and allows the deposition of nanostructured coatings on substrates of various chemical natures and geometries.

A significant contribution to the development of transient electrolysis as a research area of technical electrochemistry was made at the Novocherkassk electrochemical school [72-81].

In works [72,73], the behaviors of a number of metals (platinum, nickel, iron, silver, gold, lead, cobalt and others) were studied in alkaline and neutral solutions during transient electrolysis, and the mechanism of their destruction was determined. Additionally, a whole series of works on an accelerated charge, the formation of alkaline accumulators and the definition of their degree of charge was carried out. [72,73].

The development of directed synthetic methods for new composite materials on the basis of transition metal oxides is one of the promising directions in modern science. The wide interest in composite materials on the basis of $\mathrm{Mo}, \mathrm{Co}, \mathrm{Ni}, \mathrm{Fe}, \mathrm{V}$ oxides is determined by the complexity of areas of their use: as catalystically active materials, sensor, solion, photo and electrocatalytic devices, solid-phase converters of light energy and anti-corrosion materials. 


\section{Composite oxide materials}

Metal oxidation is one of most widely used methods of metal corrosion protection. In this case the oxide film is formed, mainly, due to oxidation of a substrate material during its anodic polarization. However, the electrochemical synthesis of complex oxide materials by anodic deposition from mixed aqueous solutions of salts of co-precipitated metals is of great interest $[82,83]$. The positive aspect of electrolytic synthesis is the opportunity to obtain homogeneous structured systems which components (unlike conventional mechanical mixtures) can interact at a molecular level and have higher electrochemical characteristics. Legagneur et al. [84] showed that complex vanadium-manganese oxides, which are obtained by electrolytic deposition from aqueous solutions, have higher electrochemical activity in comparison to the individual components.

\subsection{Electrolytic composite oxide materials}

The interest in composite oxide coatings is largely a result of the potential to obtain composite materials on their basis and the opportunity to develop thin film ballastless cathodes of lithium cells by direct deposition of oxide material as a compact coating on a conductive substrate [85-87].

Nagirnyj et al. [88] found that during electrolysis, vanadium and manganese oxides codeposit as the $\mathrm{V}_{2} \mathrm{O}_{5}-$ $\mathrm{MnO}_{2}$ double oxide system from mixed aqueous solutions containing the ions $\mathrm{VO}^{2+}$ and $\mathrm{Mn}^{2+}$.

The kinetics of these processes are largely determined by concurrent oxidation and reduction reactions between ions involved in an electrode process and products of anodic oxidation formed during different stages. Comparison of the standard electrode potentials for reactions occurring on electrodes show that their values are close [89].

$$
\begin{array}{ll}
2 \mathrm{VO}^{2+}+3 \mathrm{H}_{2} \mathrm{O}-2 \mathrm{e}^{-} \rightarrow \mathrm{V}_{2} \mathrm{O}_{5}+6 \mathrm{H}^{+}, & E^{0}=1.10 \mathrm{~V} \\
\mathrm{Mn}^{2+}+2 \mathrm{H}_{2} \mathrm{O}-2 \mathrm{e}^{-} \rightarrow \mathrm{MnO}_{2}+4 \mathrm{H}^{+}, & E^{0}=1.23 \mathrm{~V} \\
2 \mathrm{H}_{2} \mathrm{O}-4 \mathrm{e}^{-} \rightarrow \mathrm{O}_{2}+4 \mathrm{H}^{+}, & E^{0}=1.23 \mathrm{~V}
\end{array}
$$

Therefore, the above oxidation and reduction reactions can occur at intermediate and final stages of an anodic process when shifting equilibrium to one or another direction due to changes of the ratio of concentrations of original components.

In [90], complex binary systems were obtained as a result of electrolytic codeposition of oxides of manganese, cobalt, nickel, and chromium from mixed aqueous solutions of salts of codeposited metals under different electrolytic conditions. Electrodeposition was carried out on anodes made of Type 12189 (12H12N9T) stainless steel at $j_{a}=7.5-25.0 \mathrm{~mA} \cdot \mathrm{cm}^{-2}$ and $85^{\circ} \mathrm{C}$. The presence of a basal oxide which can be deposited by itself on an anode having quite a high yield, for example, oxides of manganese and cobalt, is a necessary condition for electrolytic synthesis of such materials.

Nagirnyj et al. [91] reported that during electrolytic deposition of cobalt(III) oxide in the presence of nickel(II) and chromium(III) ions from aqueous sulfate solutions the $\mathrm{Co}-\mathrm{Ni}$ and $\mathrm{Co}-\mathrm{Cr}$. complex binary oxide systems are deposited on the anode. The most favorable conditions for quantitative deposition of oxides on an anode are achieved at $80-85{ }^{\circ} \mathrm{C}$, $\mathrm{pH} 2.5-3.0$ and an anodic current density $j_{a}=10 \mathrm{~mA} \cdot \mathrm{cm}^{-2}$.

The anodic deposition of a vanadium oxide from vanadium(IV) oxide sulfate solutions in the presence of nickel ions results in the formation of complex vanadium-nickel oxide systems, which are characterized by increased electrochemical activity [92]. To obtain anodic deposits as V-Ni binary systems with the content of alloying phase $0.10-20$ (mass.)\%, the electrolysis is carried out using vanadium(IV) oxide sulfate and nickel sulfate solutions with total concentration of $40-45 \mathrm{~g} \cdot \mathrm{l}^{-1}$, at $80-85^{\circ} \mathrm{C}, \mathrm{pH} 2.0-2.2$ and $j_{a}=7.5-10 \mathrm{~mA} \cdot \mathrm{cm}^{-2}$. Transition metal oxides enable one to obtain electrical materials, ranging from high resistance dielectrics to high temperature superconductors.

The possibility of obtaining molybdenum oxide both as fine deposits and as compact coatings on a surface of stainless steel and aluminum should be referred to the benefits of a method of its electrosynthesis [90,93-98]. The scientific and technological foundations for quantitatively obtaining vanadium, cobalt oxides and two-phase systems based on manganese dioxide as dispersed deposits by electrolytic anodic deposition from aqueous solutions of the corresponding salts are reviewed in work [98].

Nickel and cobalt oxides obtained by electrolytic deposition on the surface of steel from aqueous solutions [99] can be used as electrode materials $[100,101]$, in heterogeneous catalysis $[102,103]$ and as an active element of gas sensors [104, 105].

Composite coatings based cobalt and nickel oxides are used in electrochromic devices [106]. High efficiency and super frequency dielectrics based on complexes of cobalt and nickel oxides have also been developed [107].

The kinetics for anodic processes during electrodeposition of $\mathrm{V}_{2} \mathrm{O}_{5}$ from aqueous solutions of vanadium(IV) oxide sulfate $\left(\mathrm{VOSO}_{4}\right)$ in the presence of $\mathrm{Na}^{+}$ions is considered in [108]. 
During the process of electrodeposition, tungsten and molybdenum oxides are able to incorporate a metal matrix (for example, nickel) with the formation of composite films which are characterized by significant wear resistance, especially in the process of mixed oxide formation [109]. Mixed oxide systems based on vanadium and molybdenum are used either as massive or supported catalysts for the partial oxidation and oxidative dehydrogenation of organic compounds [110]. These catalysts are usually obtained by igniting a mixture of oxides in air at $650{ }^{\circ} \mathrm{C}$ and higher, by their alloying [111] or by vaporization of aqueous solutions of ammonium salts of vanadium and molybdenum with their subsequent thermolysis [112]. Such methods for obtaining catalysts are very time-consuming. At the same time, the use of an electrochemical method to obtain such oxide systems is very attractive because it does not require complex equipment; it is simple, economical unlike other methods, and in some cases it allows one to obtain oxide coatings with specified composition by controlling the electrolyte composition and electrolysis mode.

Recently, the areas of chemistry dealing with electrochemical synthesis and research of thin layer metal polymers and their composite coatings have been widely developed [113]. Metal complex polymer-immobilized systems have widely-ranging practical applications [114]. The possibility of obtaining non-porous double-layer magnetic matrices based on cobalt ferrite to immobilize biologically active substances in a silicon matrix was examined in [115].

Pimkov et al. [116] developed methods for the chemical activation of polypropylene materials and subsequent immobilization of a cobalt phthalocyanine complex in them.

The Japanese researchers [117] offered the composition of electrolyte to obtain a polymeric composite coating with high corrosion resistance and adhesion based on zinc, cobalt, nickel and iron oxides

As a result of the hemisorption process, polymer-immobilized composite coatings of $\mathrm{Fe}_{3} \mathrm{O}_{4}$ [118] that can be used in biotechnology were obtained, using polyamine-, polylactam- and polyacrylamide-based polymers.

A polymer-immobilized nickel oxide-based composite coating on a titanium surface haviing high anti-microbial properties was obtained by an electrochemical method using direct current [119].

Analysis of the present state of the art showed that the above electrolytic oxide materials were obtained by deposition of their salts from aqueous solutions on an anode (mostly) or on a cathode using direct current polarization. Currently, the immobilization of metal oxides and metal-complexes into different polymer arrays is carried out, mainly, by pure chemical methods [120].

\subsection{Selective composite oxide coatings}

The electrochemical methods which allow one to obtain anodic aluminum oxide (AOA) with specified functional properties are quite simple. Their properties can be changed by filling oxide pores with one or more organic or inorganic substances that are added to the electrolyte solution. To obtain selective coatings based on AOA using an asymmetric alternating current seems to be a promising line of research.

Special units, called "solar collectors", are used to convert solar electromagnetic radiation into thermal energy. The main element of a collector is an absorbing panel (an absorber or a heat receiver). This captures the energy in sunlight by converting it into heat and transmits it to a heat transfer agent. The panels are usually made of aluminium, copper or steel.

The ideal surface of a heat receiver should be able to absorb in the visible part of the electromagnetic (EM) spectrum well and radiate little if any of the absorbed energy in the infrared region. Such an ideal surface is called a selective surface and a coating which allows one to obtain such a surface is called selective or optically selective.

Selective coatings must meet certain criteria. Their effectiveness is characterized by:

- integrated solar energy absorption coefficient, $\alpha_{\text {sol }}$, which should be high;

- relative integrated intrinsic radiation coefficient, $\varepsilon$, which should be low throughout the whole spectral range of solar radiation;

- selectivity expressed by the ratio of absorptivity to radiation, $\alpha_{\text {sol }} / \varepsilon$. The higher this ratio is, the higher the quality of a selective coating is because the collector converts EM radiation of the Sun into heat more efficiently.

Current state-of-the-art collectors have $\alpha_{\text {sol }}$ values that approach $94.0-96.0 \%(0.94-0.96)$, and $\varepsilon$ values that do not exceed $12.0-16.9 \%(0.12-0.16)$. To minimize energy losses, it is essential that the $\alpha_{\text {sol }}$ coefficient value tends to unity in the visible and near infrared regions of the EM spectrum, and the reflection coefficient value for the surface should tend to unity in the wavelength region intrinsic to thermal radiation [121].

A layer with a large reflection coefficient in the long-wavelength region of spectrum, for example, copper, nickel, molybdenum, silver, aluminium is usually applied on a surface which must be given selective properties. Another translucent layer with a high absorption coefficient in the visible and near infrared regions is also applied to this layer. Many oxides have such properties. Thus, in the UV and visible regions, the optical properties 
of selective coatings should be very close to properties of an absolute black-body, and in the infrared region of spectrum they should be very close to properties of an absolutely white one. The development of such coatings is quite a difficult task, so the technology of their production is commercially confidential. Multilayer selective coatings are known for solar collectors having two layers, one of which is made as an aluminum oxide film which has pores filled with metal particles, for example, nickel, and another possibility is a tin dioxide film which is placed first along the solar rays [122]. An additional layer, in the form of a hydrated $\mathrm{Al}_{2} \mathrm{O}_{3}$ film, is located between these two layers. The $\alpha_{\text {sol }} / \varepsilon$ ratio is about $4.0-5.0$ for coatings of this type because of the relatively high value of the coefficient $\varepsilon$ and the low magnitude of $A_{c}\left(A_{c} \geq 0.9 ; \varepsilon \geq 0.2\right)$.

The absorbing coating consisting of a solid amorphous carbonaceous film [123] was deposited on metal electrodes from the glow discharge in organic or organoelement compounds. The coating has high adhesion characteristics but a low integrated solar energy absorption coefficient $\left(\alpha_{\text {sol }}=0.85\right)$. This is because the coating has high refraction indices, $\mathrm{n}$, in the visible part of the EM spectrum. But selective coatings have optimum optical properties only at an optimum thickness, which should not exceed the $\lambda_{0} / n$ value $\left(\lambda_{0}-\right.$ a wavelength corresponding to maxima of solar radiation spectrum).

The method of obtaining a multilayered selective coating [124] on aluminum foil by depositing a titanium layer in vacuo and subsequent vacuum reactive evaporation of nonstoichiometric titanium metalloids is known. The latter is usually obtained by reactive evaporation of $\mathrm{CO}_{2}$ or $\mathrm{N}_{2}$ in the atmosphere under the partial pressure of each gas within $(2.5-8.0) \cdot 10^{-2} \mathrm{~Pa}$, then amorphous carbonaceous material is precipitated in glow discharge in vacuum in organic or organoelement compound vapor under partial gas pressure within the range of $10-20 \mathrm{~Pa}$. The selective coating obtained by this method has rather low radiation coefficient $\varepsilon=0.035$ and $\alpha_{\text {sol }}=0.84-0.87$. The latter is very low therefore to increase the absorption coefficient $\alpha_{\text {sol }}$, Dyachshin et al. [124] increased the discharge current density to $0.2-0.3 \mathrm{~A} \cdot \mathrm{dm}^{-2}$ and the discharge burning voltage to $400-450 \mathrm{~V}$ of an alternating current with the frequency of $50 \mathrm{~Hz}$. Only in this case did the $\alpha_{\text {sol }}$ value increase from 0.87 to 0.94 . As is obvious, this method of obtaining a selective coating is technologically complicated and very time-consuming.

A multilayered selective coating that consists of two layers was obtained by Dyachshin et al. [125] by consistent precipitation from a glow discharge under organic or organoelement compound vapors on the metal surface of an aluminum collector. The first layer was deposited from a glow discharge in benzol vapors under a pressure of $1 \cdot 10^{-2} \mathrm{mmhg}$, a discharge density $0.7 \mathrm{~A} \cdot \mathrm{m}^{-2}$, a discharge burning voltage $4.0 \mathrm{kV}$ at a frequency of $50 \mathrm{~Hz}$.

The second layer of the coating is located directly on the first one and is deposited from the glow discharge in benzol vapors under a pressure of $1 \cdot 10^{-2} \mathrm{mmhg}$, discharge density $2-3 \mathrm{~A} \cdot \mathrm{m}^{-2}$, discharge burning voltage $400 \mathrm{~V}$ of AC at a frequency of $50 \mathrm{~Hz}$. This type of coatings has an integrated absorption coefficient $\alpha_{\text {sol }} 0.92-0.94$ and radiation coefficient $\varepsilon=0.07-0.08$ at $100{ }^{\circ} \mathrm{C}$. The efficiency of solar power conversion is $11.5-13.5$.

A multilayered absorbing coating was obtained by Golovkov and Verbitsky [126]. The coating contained two dielectric layers, between which there was an operated layer made in the form of a thin sprayed graphite film and a lattice made of sprayed metal strips. The process for forming a selective coating using this method is very time-consuming and ineffective.

Multilayered absorbing coatings based on fine ferromagnetic, metal or graphite particles of inductive and capacitor elements dispersed over the entire surface can be obtained [127].

The selective coating can be obtained by an electricity-free method using PbS, black copper and black chrome, $\mathrm{TiN}_{x} \mathrm{O}_{y}, \mathrm{Ni}-\mathrm{NiO}_{x}, \mathrm{Al}_{2} \mathrm{O}_{3}$ in the presence of fine dispersion of $\mathrm{Ni}, \mathrm{Co}, \mathrm{Mo}, \mathrm{W}, \mathrm{Pt}$ [128].

When developing light absorbing coatings for space devices [129], a $\mathrm{CuO}$ coating on the surface of copper with a high absorption coefficient and a low reflective power was obtained. These coatings were also used as an absorber in solar collectors. To increase a solar energy absorption coefficient, however, they were deposited on rough surfaces. As a result, the light flux stayed on a surface because of its multiple re-reflection in the light traps which were formed by the surface's texture. To roughen metal substrates, they were sandblasted with $0.2-0.5 \mathrm{~mm}$ silicon carbide particles. Nevertheless, the coatings had a high radiatability.

To obtain selective copper-based coatings, the black coloring of copper in alkaline solution was used [130]. The $\mathrm{CuO}$ thin film obtained had properties of a filter: it absorbed the visible light and had a high reflective ability for long-wavelength infrared radiation. Such a film does not release heat which develops from solar radiation of a more short-wavelength part of spectrum in the thin layer of copper oxide.

Thus, depending on the method of surface preparation and oxidation time, it is possible to obtain selective coverings with different optical properties. Cheap light absorbing coatings in the form of BT -577 black bituminous enamel and No. 164 black enamel can be also used as selective coatings when there is glassifying with a "thermal mirror" made of a $\mathrm{Zr}_{2} \mathrm{O}_{3}$ or $\mathrm{SnO}_{2}$ thin film. These films are transparent in the visible range of solar radiation $(\lambda$ from 400 to $800 \mathrm{~nm}$ ) but reflect the infrared radiation rather well, which results in a more effective transformation of solar radiation to heat. However, these coatings have low Ac values and high $\varepsilon$ values. 
Moldovanov et al. [131] obtained a selective coating which consisted of aluminum particles precipitated in nitrogen-containing plasma. Atoms of nitrogen create strong covalent bonds with surrounding aluminum atoms which results in an aluminum lattice distortion and transformation of solar into thermal energy. When obtaining selective coatings which reflect or absorb optical radiation selectively, various pigments are also used [132]. They are added to the selective coatings composition in a dispersion form [133]. $\mathrm{ZnO}, \mathrm{TiO}_{2}, \mathrm{MgO} \mathrm{Al}_{2} \mathrm{O}_{3}$ and others are referred to pigments that reflect optical radiation in the short-wavelength region. $\mathrm{Fe}_{3} \mathrm{O}_{4}, \mathrm{Sb}_{2} \mathrm{O}_{3}$ and carbon-based pigments absorb optical radiation over the entire optical range from visual to infrared, therefore, they are used as solar absorbers.

Metal-based thin films that absorb visible light and passing infrared radiation are the common type of a selective coating. Among these are coatings from black chrome and black nickel which are applied on nickel, zinc, tin or copper substrates using an electrochemical method. Black chrome coatings are the most promising ones, since they allow one to obtain the required optical properties and have a high thermal stability. However, when depositing black chrome, the density of an electric current is almost a hundred times higher than that for black nickel, therefore, the cost of black chrome selective coatings is high.

Coating selectivity can also be provided solely by geometrical factors: surface asperities should be greater than the wavelength of light in the spectrum of visible and near IR regions and less than a wavelength corresponding to its surface intrinsic radiation. Such a surface for the first of the above spectrum regions will be black, and for the second one it will be mirrored. Surfaces with a dendritic or porous structure with appropriate sizes for the dendritic needles and pores have selective properties.

Thus, the efficiency of a solar collector can be increased by using selective absorbing coatings on a heat absorber surface which absorb the visible part of the EM spectrum well and do not practically radiate in the infrared region of spectrum [134].

As it appears from the reviewed methods of obtaining selective coatings, the mature methods at present are as follows: chemical vapor deposition, vacuum dusting, galvanic and chemical ones. The methods listed have a number of disadvantages: high process energy intensity (more than $200 \mathrm{~kW} \cdot \mathrm{m}^{-2}$ ); multilayer coatings and their deposition time; expensive and ecologically harmful components; insufficiently high transformation efficiency for solar energy. According to the current standards [134] for good selective coatings, the absorption ability has to be not less than $92 \%(0.92)$, and the radiation ability - no more than $30 \%(0.3)$. Selective coatings can be deposited on such materials of a heat exchanger (absorber) as aluminum, steel, nickel, titanium, silver, copper and others. Additionally, the thickness of coatings having absorbing properties should not exceed $1 \mu \mathrm{m}$. While developing selective coatings, their cost is also an important factor, since the use of one type of a selective coating or another can result in either decrease of costs for the collector's other elements or increase them and, thus, make their characteristics worse.

The use of an asymmetric alternating current to obtain selective coatings has received almost no attention in the literature. Meanwhile, the use of an asymmetric alternating current, which allows one to regulate the structure of an oxide film and the amount of impurities in it, is very promising for obtaining such coatings.

When developing a technique to obtain optically selective coatings on the surface of Type AD 31 and Type A5M aluminum alloy using a transient electrolysis method, Bespalova et al. [78] paid much attention to a surface preparation to receive a developed microstructure. Therefore a stage of zinc electrodeposition was added to the surface preparation methods. As a result of interaction of the components of a zinc electrolyte, the reaction of sodium tetrahydrozincate formation proceeds as follows:

$$
\mathrm{ZnO}+2 \mathrm{NaOH}+\mathrm{H}_{2} \mathrm{O} \rightarrow \mathrm{Na}_{2}\left[\mathrm{Zn}(\mathrm{OH})_{4}\right]
$$

Heating the zinc solution increases the rate of the reaction (1) and the content of sodium tetrahydrozincate in the solution. While immersing a sample of aluminum alloy into a sodium tetrahydrozincate solution, the process of zinc chemical reduction takes place on its surface. The structure and the specific surface of the aluminum sample change due to a contact exchange of aluminum atoms to zinc atoms in a crystal lattice. The zinc layer was removed from the surface of an aluminum alloy using orthophosphoric acid solution [78]. When it was removed, the surface had a very developed microstructure. The latter was confirmed by the images of the surface of Type AD 31 and Type A5M aluminum alloys that were received by means of high vacuum scanning electron microscopy (Fig. 1) after its preparation. The surface consisted of pyramid-shaped projections, with their base being $0.8-1.5$ microns and their height -0.5 to 1.5 microns. To obtain selective coatings is difficult, and in this case, it is also complicated by the fact that the electrolytes used to oxidize aluminum and its alloys [135-142] cannot be used, as they do not allow one to obtain porous coatings with thickness not more than 1 micron, simultaneously filling pores with a highly-dispersed metal. But heavy coatings have high radiatabilities. 


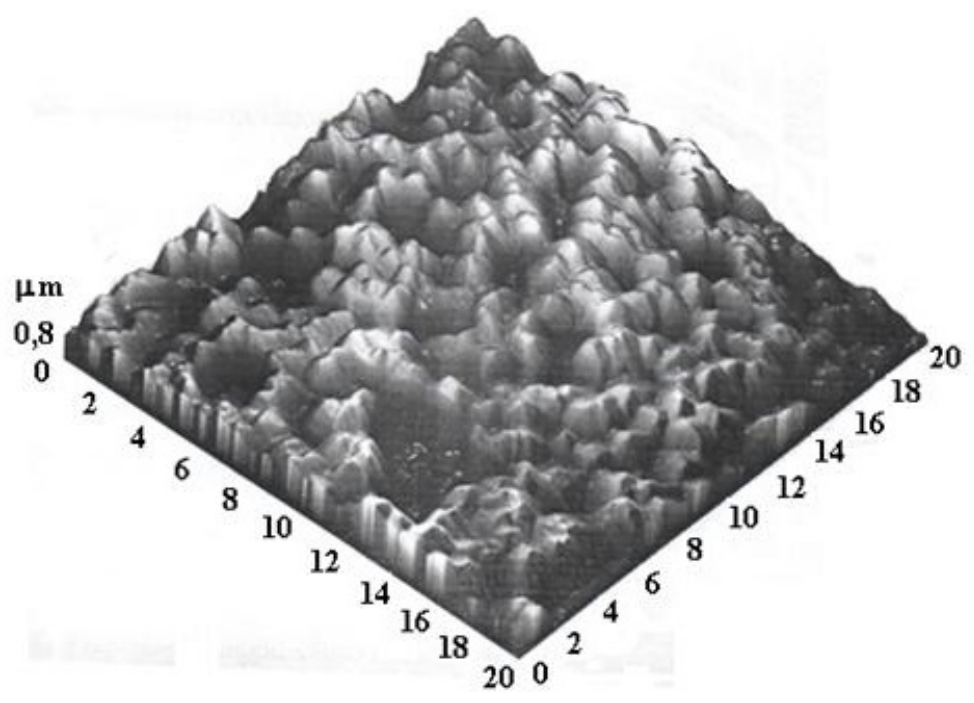

FIG. 1. Morphology of Type AD 31 and Type A5M aluminum surface after pretreatment

The composition of an electrolyte solution containing: formalin $-1.5 \mathrm{~g} / \mathrm{l}$; citric acid - $1.0 \mathrm{~g} / \mathrm{l}$; ammonium sulfate $\left[\mathrm{Al}_{2}\left(\mathrm{SO}_{4}\right)_{3} \cdot 18 \mathrm{H}_{2} \mathrm{O}\right]-35.0 \mathrm{~g} / \mathrm{l}$; nickel sulfate $\left[\mathrm{NiSO}_{4} \cdot 7 \mathrm{H}_{2} \mathrm{O}\right]-35.0 \mathrm{~g} / 1$ was developed [78]. The oxidation mode when obtaining selective coatings was the following: the ratio between average cathode and anode current densities was $2: 1$; the temperature $-25 \pm 5{ }^{\circ} \mathrm{C}$; the time $-150.0 \mathrm{~s}$. During asymmetric alternating current electrolysis in aqueous solutions of nickel salts, nickel hydroxides are usually formed $[72,76]$ which for nickel oxidation levels within the range of ("+2" $\div$ “+3"), form a continuous number of solid solutions in nickel oxide [143] corresponding to the $\mathrm{NiOOH}$ formula $x$, where $x$ changes from 2 to 1.2 .

The process of deposition for hydrated nickel ion (an aquacomplex) from solution on an electrode surface in the form of a solid phase proceeds by equation:

$$
\left(\mathrm{Ni}^{2+}\right) \cdot y \mathrm{H}_{2} \mathrm{O}-2 \mathrm{e}^{-}+2 \mathrm{H}_{2} \mathrm{O} \rightarrow\left(\mathrm{NiOOH}_{2}\right) \cdot x \mathrm{H}_{2} \mathrm{O}+2 \mathrm{H}^{+} .
$$

One can suggest two methods for this process development. The first one deals with the formation of coatings due to chemical precipitation of nickel hydroxides from aquacomplex solutions when basifying a near-electrode layer near the electrode surface:

$$
\left(\mathrm{Ni}^{2+}\right) \cdot y \mathrm{H}_{2} \mathrm{O}+2 \mathrm{OH}^{-} \rightarrow \mathrm{Ni}(\mathrm{OH})_{2} \cdot x \mathrm{H}_{2} \mathrm{O}+(y-x) \cdot \mathrm{H}_{2} \mathrm{O} .
$$

While cycling under the influence of an asymmetric alternating current, the film charge in an anode semiperiod is:

$$
\mathrm{Ni}(\mathrm{OH})_{2} \rightarrow \mathrm{NiOOH}_{2}-z \mathrm{e}^{-}+z \mathrm{OH}^{-} \rightarrow \mathrm{NiOOH}_{2-x}+z \mathrm{H}_{2} \mathrm{O},
$$

and the discharge in a cathodic semiperiod which occurs is:

$$
\mathrm{NiOOH}_{2}+z \mathrm{e}^{-}+z \mathrm{H}_{2} \mathrm{O} \rightarrow \mathrm{NiOOH}_{2}+z \mathrm{OH}^{-} .
$$

The galvanic nickel deposition in aluminum oxide pores $\mathrm{Al}_{2} \mathrm{O}_{3}$ can also proceed in a cathodic semiperiod:

$$
\mathrm{Ni}^{2+}+2 \mathrm{e}^{-} \rightarrow \mathrm{Ni},
$$

and the subsequent oxidation can proceed in an anode semiperiod due to oxygen evolution:

$$
\begin{aligned}
& 4 \mathrm{OH}^{-} \rightarrow \mathrm{O}_{2}+2 \mathrm{H}_{2} \mathrm{O}+2 \mathrm{e}^{-} \quad \text { (in an alkaline medium) }, \\
& 2 \mathrm{H}_{2} \mathrm{O} \rightarrow \mathrm{O}_{2}+4 \mathrm{H}^{+}+2 \mathrm{e}^{-} \quad \text { (in an acidic medium). }
\end{aligned}
$$

The above equations $(2-8)$ represent a simplified record. In fact, an oxide film has water molecules in its composition, and ions in solution represent aquacomplexes. In addition to reaction (8), however, a nickel oxidation can proceed via:

$$
\mathrm{Ni}+2 \mathrm{H}_{2} \mathrm{O} \rightarrow \mathrm{NiOOH}_{2}+2 \mathrm{H}^{+}+2 \mathrm{e}^{-} \text {. }
$$

The selective coating obtained by the method [78] consists of aluminum oxide particles having sizes ranging from 20 to $70 \mathrm{~nm}$ (Fig. 2). The raster electron microscopy showed that in aluminum oxide particles, there is highly-dispersed nickel which is evenly distributed on the entire surface (Fig. 3). 


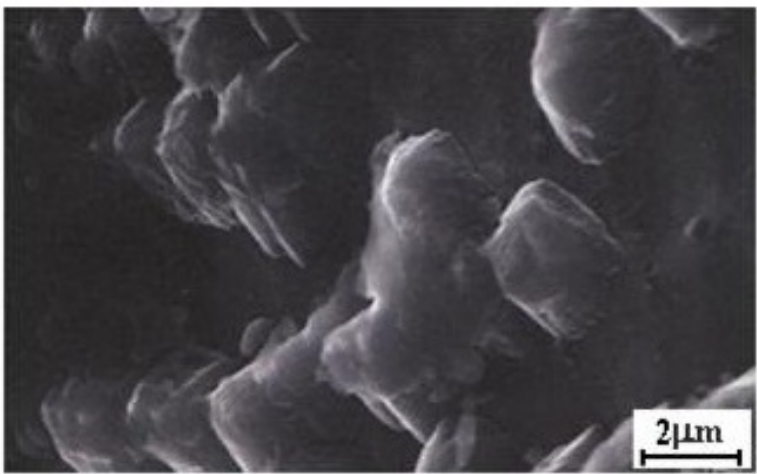

$\mathbf{a}$

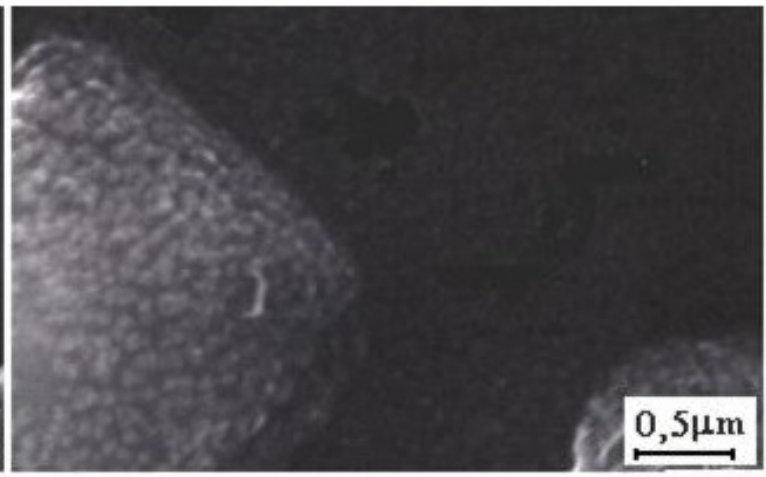

b

FIG. 2. SEM - image of the selective coating on the surface of aluminum: a - general view of the surface at the angle of $45^{\circ}, \mathrm{b}$ - image of fine-dispersed nickel in nanoscale hollows of aluminum oxide

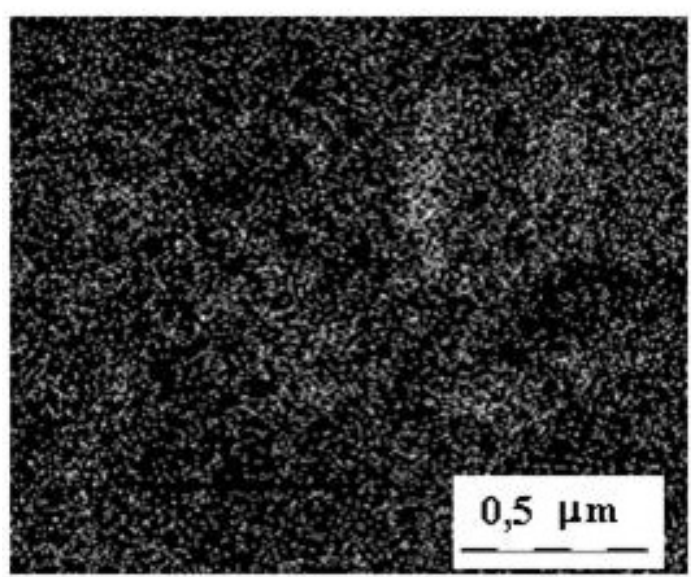

FIG. 3. Image of a selective coating surface in the $\mathrm{X}$-ray radiation of $\mathrm{NiK}_{\alpha}$-line. Density of white points is proportional to the nickel content

This suggests that the coating represents aluminum oxide nanotubes filled with nickel nanoparticles. Thus, in pores of oxides, a highly-dispersed nickel is deposited in a cathodic semiperiod according to reaction (6).

Gnedenkov et al. found [144] that in solutions and in powder samples complex compounds in an anion form of aluminum with carboxylic acids can be formed by carboxy groups at $\mathrm{pH}=2-4$, carboxyl groups and hydroxy groups at $\mathrm{pH}=4-9$ and only hydroxy groups at $\mathrm{pH}=9-10$. The similar complex formation of nickel with citric acid is likely to take place to obtain selective coatings in an electrolyte solution.

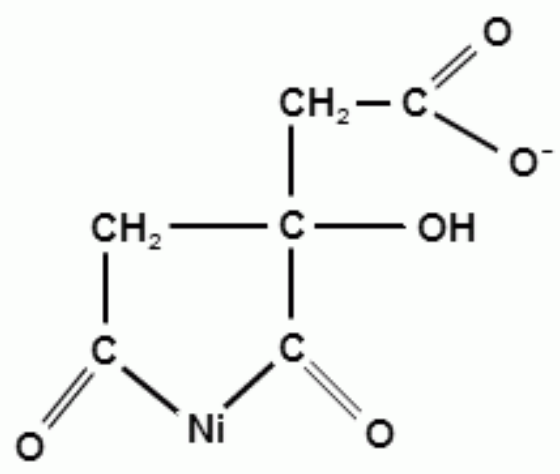


This process enables one to suppress the formation of nickel hydroxide in a cathodic semiperiod because of alkalinizing near-cathode space and makes the lifting of nickel to an electrode surface easier where it is deposited in the form of highly-dispersed nickel in aluminum oxide pores.

The presence of a citric acid in the composition of an electrolyte [78] besides the processes of complex formation also provides high adhesion for an optically selective coating to a substrate, creating an acid medium in which the partial oxidation process for an aluminum alloy with formation of a thin layer of aluminum oxide takes place. Under optimum conditions, the optical selective coatings with absorption coefficient of $93.5 \%$ and radiation coefficient of $6.0 \%$ were obtained using the method of Type AD 31 and Type A5M aluminum alloys surface preparation developed by Bespalova et al. [78]. These data are among the best characteristics of optical selective coatings manufactured by industry for helioplants. The development of an effective surface allowed reduction of the probability for a secondary photon to leave surface coatings because of its repeated rereflection in light traps formed by the surface relief.

To increase the thermoreceptor properties of optical selective coatings, it is necessary to have a transparent layer that is resistant to the impact of ultra-violet radiation on its surface. Initially, fluoroplastic (type F-3MV, F-32LN) and silicone varnishes (type KO-85) were investigated as a transparent layer by Bespalova et al. [44]. The most promising of them was the $1-3$ mass $\%$ solution of F-32LN fluoroplastic varnish. The presence of this layer allowed them to increase the absorption coefficient to $95.0 \%$ and slightly increased the radiating power to $9.0 \%$.

According to the results of the research, the developed optical selective coatings had high heat stability that confirmed the possibility of their use in helioplants.

Thus, on the surface of aluminum alloys, optically-selective coatings were obtained under polarization by an asymmetric alternating current that enabled researchers to obtain single-layer coatings with exceptional optical properties within $2.5 \mathrm{~min}$; to reduce power consumption of the process to $10 \mathrm{~kW} \cdot \mathrm{m}^{-2}$; to exclude the use of expensive components; and to ensure ecological safety of coatings formation.

\section{Catalytically-active composite materials based on transition metal oxides}

The development of composite coatings based on transition metal oxides, including molybdenum oxide compounds with a wide range of practical application [145-148] is a promising trend of surface modification.

Composite coatings based on molybdenum oxides are especially attractive because of their atypical chemistry resulting from multiple valence states. In addition, they are stable, have significant activity and selectivity in different processes [149].

Molybdenum oxide compounds can be obtained by a hydrothermal method [150], pyrolysis of various oxide organic precursor molybdenum compounds [151] chemical dehydration of colloidal solutions [152] and also by an electrochemical method using a direct current from molybdate solutions [153]. Among the methods for directed synthesis of new catalytically active composite materials based on molybdenum, cobalt, nickel, iron, manganese, vanadium oxides, electrochemical methods are very promising. The electrolytic depositions of molybdenum oxides in the form of specific modifications: $\mathrm{Mo}_{4} \mathrm{O}_{11}, \mathrm{Mo}_{8} \mathrm{O}_{23}, \mathrm{MoO}_{2}, \mathrm{MoO}_{3}, \mathrm{Mo}_{18} \mathrm{O}_{52}$ and $\mathrm{Mo}_{9} \mathrm{O}_{26}$ from ammonium molybdate and sodium molybdate solutions are the subject of a large number of studies [93,97, 150, $151,154]$. Electrochemical methods for obtaining such systems from aqueous solutions have a number of specific characteristics because the state of Mo (VI) in an aqueous solution has certain impact on the mechanism of electrochemical reactions. The latter is caused by the fact that depending on the concentration of molybdenum containing particles and $\mathrm{pH}$ of the solution, various isopoly compounds are formed.

A unique feature of obtaining molybdenum-based coatings from aqueous solutions is that they cannot be obtained in pure form. The most common elements of such coatings are $\mathrm{Co}, \mathrm{Ni}, \mathrm{Fe}$ [155], which have a catalytic effect on electrochemical molybdate ions reactions. Molybdenum electrolytes are stable only at $\mathrm{pH} 3.5-5.0$, therefore hydroxy acids or their salts are added into their composition, along with transition metal elements.

The reduction of the large molybdate- ion $\mathrm{MoO}_{4}^{2-}$ is a very complex process which involves electron and proton transfer processes. It proceeds in a stepwise manner, i.e. by individual elementary stages. In the case of low molybdate concentrations, the formation of $\mathrm{Mo}-\mathrm{Ni}$, Mo $-\mathrm{Co}$, Mo $-\mathrm{Fe}$ alloys will occur in the solution as a result of induced co-precipitation [156-158], proceeding through the formation of intermediates. Monovalent ions, radicals (in the presence of hydroxy acids in the electrolyte solution) and complex compounds with varying degrees of stability can act as intermediates during reaction. The nature of the intermediates, however, is not adequately studied, and the evidence of their existence on the surface or in solution is indirect. Nevertheless, one must not ignore this, as they can determine the rate and direction of an electrochemical process.

The primary process in the formation of coatings from solutions containing transition metal compounds is the deposition of iron group metals, and molybdenum deposits because of its ions adsorption by hydroxy forms of 
nickel, cobalt or iron $\left(\mathrm{CoOH}_{a d s}^{+} \mathrm{NiOH}_{a d s}^{+}\right)$, which cover the electrode. In case of higher $\mathrm{MoO}_{4}^{2-}$ content in an electrolyte solution, the electrical deposition of alloys becomes impossible and the products of partial reduction of molybdate ions deposits on the cathode. They represent both simple and complex oxide systems which are catalysts for the discharge of protons. The oxide film formed acquires electronic conductivity; its further reduction stops and only hydrogen reduction proceeds on the surface [155].

The formation of molybdenum oxides is catalyzed by iron metal group citrate complexes, for example, by a CoCit complex $[159,160]$ :

$$
\mathrm{MoO}_{4}^{2-}+2 \mathrm{H}_{2} \mathrm{O}+2 \mathrm{e}^{-} \stackrel{\text { CoCit }}{\longrightarrow} \mathrm{MoO}_{2}+4 \mathrm{OH}^{-}
$$

The presence of cobalt in the solution determines if one obtains molybdenum oxides at low concentrations, with substoichiometric molybdenum oxides being formed, whose color is associated with the presence of oxygen vacancies [161], and the potentials which are more positive than minus $0.125 \mathrm{~V}$ can be attributed to the cobalt molybdenum oxidation [158]. The high efficiency of molybdenum oxide formation in the presence of $\mathrm{Co}$ (II), $\mathrm{Fe}$ (II) and $\mathrm{Ni}$ in the solution may be connected with simultaneous CoCit adsorption on molybdenum and the presence of electroactive colloidal forms of $\left[\mathrm{Fe}(\mathrm{OH})_{x}\right] \mathrm{Fe}^{2+},\left[\mathrm{Ni}_{y} \mathrm{Fe}_{z} \mathrm{OH}\right]^{n+}$ or $\left[\mathrm{Co}_{y} \mathrm{Fe}_{z} \mathrm{OH}\right]^{n+}$ in the reaction layer which reduces hydrogen evolution [162].

In [163], it was determined that reduction of hexavalent molybdenum in ammonium citrate electrolytes occurs mainly from heptamolybdate ions. Ammonium ions increase the percentage of heptamolybdate in the solution which increases their reduction, and the presence of citrate has a depolymerization effect on hexavalent molybdenum compounds. The citrate-ion is a hard ligand, so it could retain pentavalent molybdenum compounds in a solution and prevent its disproportionation with $\mathrm{MoO}_{2}$ formation. The quantitative ratio of citrate ion and ammonium ion allows one to control the rate of formation of molybdenum oxide and its quantity.

The degree of molybdenum oxidation in oxide films was (IV), (V) and (VI). In the presence of ammonium ions, Mo(VI) reduction to intermediate oxidation states is facilitated. One can suggest that ammonium ions, in addition to cobalt ions serve as donors of protons that are necessary to reduce molybdenum oxygen-containing compounds. However, the main factors that affect the formation of hydroxide forms, the process of polymerization and chemisorption processes are the $\mathrm{pH}$-value and the electrolyte temperature.

The deposition of molybdenum oxides takes place only when the potentials are more negative than some threshold value, which depends only on the electrolyte composition [159]. In the partial reduction of Mo(VI) during electrolysis of aqueous solutions of molybdates $\mathrm{MoO}_{2}[164,165], \mathrm{Mo}_{2} \mathrm{O}_{3}$ [166], $\mathrm{Mo}_{2} \mathrm{O}_{5}, \mathrm{Mo}_{3} \mathrm{O}_{8}$, nonstoichiometric compounds type $\mathrm{Mo}_{3} \mathrm{O}_{R-x}$ as well as mixed Mo (IV) - Mo (V) oxides [167] are formed. These products can be subjected to further reduction, its mechanism is still not clear [165-169]. It is significant that in solutions containing $\mathrm{Mo}(\mathrm{VI}), \mathrm{Co}, \mathrm{Ni}, \mathrm{Fe}$ and hydroxy acids various chemical reactions that lead to the formation of a wide range of compounds, including complex ones can proceed. The identification of Mo(VI) complexes is very problematic. However, citrate complexes, for example, type $\mathrm{HrMoO}_{4} \mathrm{Cit}^{(5-r)}$ [165, 169], $\mathrm{H}_{x} \mathrm{Mo}_{7} \mathrm{O}_{24}^{(6-x)-}$, NiMoO ${ }_{24} \mathrm{H}_{6}^{4-}, \mathrm{H}_{x}\left(\mathrm{MoO}_{4}\right)_{2} \mathrm{Cit}^{(7-x)-}$ and $\mathrm{H}_{x} \mathrm{MoO}_{x} \mathrm{Cit}^{(5-x)-}$ [170] are documented, which confirms that complex chemical or electrochemical processes occur during the co-deposition of molybdenum with transition metals (Co, $\mathrm{Ni}, \mathrm{Fe}$ ) from electrolyte solutions containing hydroxy acids.

The ligand excess in the electrolyte composition is not desirable and its concentration should not be also very low. Otherwise, slightly-soluble hydroxides can be formed because of the system's stability loss in bulk solution.

The possibility of obtaining molybdenum oxides by cathodic reduction during electrolysis of aqueous solutions of sodium molybdate and ammonium heptamolybdate on the surface of steel was determined in $[93,97,154,171-$ 173], where it was supposed that under investigated circumstances several parallel reactions were realized with a certain probability for proceeding:

$$
\begin{gathered}
\mathrm{MoO}_{4}^{2-}+2 \mathrm{H}_{2} \mathrm{O}+2 \mathrm{e}^{-} \rightarrow \mathrm{MoO}_{2}+4 \mathrm{OH}^{-} \\
2 \mathrm{MoO}_{4}^{2-}+5 \mathrm{H}_{2} \mathrm{O}+6 \mathrm{e}^{-} \rightarrow \mathrm{Mo}_{2} \mathrm{O}_{3}+10 \mathrm{OH}^{-} \\
2 \mathrm{MoO}_{4}^{2-}+3 \mathrm{H}_{2} \mathrm{O}+2 \mathrm{e}^{-} \rightarrow \mathrm{Mo}_{2} \mathrm{O}_{5}+6 \mathrm{OH}^{-}
\end{gathered}
$$

According to [93,97,154,171,172], during formation of molybdenum oxides the main step is the discharge of the $\mathrm{MoO}_{4}^{2-}$ ion, whose rate largely depends on the intensity of its forestalling hydrogen evolution. The summary 
scheme of an electrode process can be represented by a number of the following chemical equations [154]:

$$
\begin{aligned}
\mathrm{MoO}_{4}^{2-}+2 \mathrm{H}^{+}+\mathrm{e}^{-} & \rightarrow \mathrm{MoO}_{3}^{-}+\mathrm{H}_{2} \mathrm{O} \\
\mathrm{MoO}_{4}^{2-} \text { ads }+2 \mathrm{H}^{+} & \rightarrow 2 \mathrm{MoO}_{3 \text { ads }}+\mathrm{H}_{2} \mathrm{O} \\
\mathrm{MoO}_{3}^{-}+2 \mathrm{H}^{+}+\mathrm{e}^{-} & \rightarrow \mathrm{MoO}_{2}^{-} \text {ads }+\mathrm{H}_{2} \mathrm{O} \\
3 \mathrm{MoO}_{3 \text { ads }}+\mathrm{MoO}_{2 \text { ads }} & \rightarrow \mathrm{Mo}_{4} \mathrm{O}_{11 \text { ads }}
\end{aligned}
$$

The given scheme reflects the sequential interdependence of electrochemical $(9,11)$ and redox $(10)$ reactions as well as the initial stage of phase transition (12). The justification for such a mechanism has not been thoroughly proven.

In addition to a $\mathrm{MoO}_{3}$ rhomboidal main phase $\mathrm{MoO}_{3} \cdot 2 \mathrm{H}_{2} \mathrm{O}, \mathrm{MoO}_{3} \cdot \mathrm{H}_{2} \mathrm{O}$ monoclinic phases and $\mathrm{MoO}_{x}(\mathrm{OH})_{y}$ crystallographic shift phase can be present in the composition of the coatings. In [174], using an electrochemical method, molybdenum oxide compounds were formed on the surface of steel, nickel and carbon from aqueous solutions containing: $\left(\mathrm{NH}_{4}\right)_{6} \mathrm{Mo}_{7} \mathrm{O}_{24} \cdot 4 \mathrm{H}_{2} \mathrm{O}-10.0 \mathrm{~g} / \mathrm{l} ; \mathrm{HF}-1.0 \mathrm{~g} / \mathrm{l}$; cathodic current density of $0.5-1.0 \mathrm{~A} \cdot \mathrm{dm}^{-2}$; electrolysis time $-10 \mathrm{~min}$ at room temperature. The cathodic deposits obtained represented such phases as $\mathrm{Mo}_{3-x}(\mathrm{OH})_{x}, \mathrm{MoO}_{3}\left(\mathrm{H}_{2} \mathrm{O}\right)_{2}, \mathrm{MoO}_{3}\left(\mathrm{H}_{2} \mathrm{O}\right)_{0.5}, \mathrm{Mo}_{3} \mathrm{O}_{8} \cdot \mathrm{H}_{2} \mathrm{O}$.

In an aqueous electrolyte solution, some dissolved forms of molybdate ions are present, depending on its $\mathrm{pH}$, which should largely determine all electrochemical processes. However, the greatest rate of molybdenum oxides formation was observed at $\mathrm{pH} 4$.

In ammonium heptamolybdate acidic solutions, $\left(\left(\mathrm{NH}_{4}\right)_{6} \mathrm{Mo}_{7} \mathrm{O}_{24} \cdot 4 \mathrm{H}_{2} \mathrm{O}\right) \mathrm{Mo}(\mathrm{VI})$ first reduces to $\mathrm{Mo}(\mathrm{V})$ and then to trivalent compounds $\mathrm{Mo}(\mathrm{III})$, and oxide $\mathrm{Mo}_{4} \mathrm{O}_{11} \cdot n \mathrm{H}_{2} \mathrm{O}$ represents an intermediate oxide compound between pentavalent $\mathrm{Mo}_{2} \mathrm{O}_{5}$ and hexavalent $\mathrm{MoO}_{3}$. The reactions which proceed on the cathode can be presented by the equations:

$$
\begin{aligned}
\mathrm{MoO}_{4}^{2-}+4 \mathrm{H}_{2} \mathrm{O}+2 \mathrm{e}^{-} & \rightarrow \mathrm{MoO}_{2} \cdot 2 \mathrm{H}_{2} \mathrm{O}+4 \mathrm{OH}^{-} \\
4 \mathrm{MoO}_{4}^{2-}+10 \mathrm{H}^{+}+2 \mathrm{e}^{-} & \rightarrow \mathrm{Mo}_{4} \mathrm{O}_{11}+5 \mathrm{H}_{2} \mathrm{O} \\
2 \mathrm{MoO}_{4}^{2-}+6 \mathrm{H}^{+}+2 \mathrm{e}^{-} & \rightarrow \mathrm{Mo}_{2} \mathrm{O}_{5}+3 \mathrm{H}_{2} \mathrm{O} .
\end{aligned}
$$

Additionally, the step below is also present:

$$
\mathrm{Mo}_{4} \mathrm{O}_{11} \rightarrow 3 \mathrm{MoO}_{3}+\mathrm{MoO}_{2} .
$$

It is also necessary to consider that molybdenum oxides formation due to a partial molybdate ion reduction proceeds with a simultaneous cycling of oxides on the surface, i.e. they are subjected to oxidation and reduction because of the changes of current direction. As a result, the spinel is formed in the active coating. A great variety of other spinel phases are considered in detail in [175-178].

When analyzing cathodic processes for the formation of molybdenum oxide phases, the processes of $\mathrm{Mo}(\mathrm{VI})$ polymerization which take place in heptamolybdate solutions with the formation of polymer cations Type $\left[\left(\mathrm{MoO}_{2}\right)\left(\mathrm{MoO}_{3}\right)_{n-1}\right]^{2+}$ or polyacids $\left(\mathrm{H}_{2} \mathrm{Mo}_{2} \mathrm{O}_{7}, \mathrm{H}_{2} \mathrm{Mo}_{3} \mathrm{O}_{10}\right)$, and redox processes leading to formation of oxide radicals are excluded from consideration. In general, the formation processes for molybdenum oxide phases and complex oxide phases using an asymmetric alternating current is very complicated. Despite the complexity of a molybdenum compound's state both in aqueous solutions and in a solid phase, however, composite materials based on oxide compounds of molybdenum can be very useful as catalytically active materials, while solving applied problems of electrochemistry. The confirmation of the latter is the research [179-182] on obtaining catalytically active coatings based on transition metal oxides ( $\mathrm{Mo}, \mathrm{Ni}, \mathrm{Co}, \mathrm{Fe}$ ) by depositing their salts from aqueous solutions under polarization by an asymmetric alternating current on the surface of St. 3 steel. The composition of electrolyte and electrolysis modes that allow one to obtain composite oxide catalytically-active coatings have been developed and optimized by Bespalova et al. [182].

Composite oxide coatings were formed on the surface of St. 3 steel pre-treated using a standard method [183] further comprising the stage of surface modification by galvanizing with a subsequent removal of a zinc layer. The main electrolyte aqueous solution components were iron(II) sulfate $\left(\mathrm{FeSO}_{4} \cdot 7 \mathrm{H}_{2} \mathrm{O}\right)$, cobalt sulfate $\left(\mathrm{CoSO}_{4} \cdot 7 \mathrm{H}_{2} \mathrm{O}\right)$, ammonium heptamolybdate $\left(\mathrm{NH}_{4}\right)_{6} \mathrm{Mo}_{7} \mathrm{O}_{24} \cdot 4 \mathrm{H}_{2} \mathrm{O}$, nickel sulfate $\left(\mathrm{NiSO}_{4} \cdot 7 \mathrm{H}_{2} \mathrm{O}\right)$, boric $\left(\mathrm{H}_{3} \mathrm{BO}_{3}\right)$ and citric $\left(\mathrm{C}_{6} \mathrm{H}_{8} \mathrm{O}_{7}\right)$ acids. The device consisting of two paralleled diodes conducting a current in different directions through the adjustable resistance was used as a technological current source.

The asymmetry parameter $\left(j_{k} / j_{a}\right)$ was equal to 1.44 ; the electrolyte temperature $-65-70{ }^{\circ} \mathrm{C} ; \mathrm{pH}-4$; and coating deposition time $-60 \mathrm{~min}$.

The X-ray diffraction data demonstrated that the phase composition of the coating substance is rather complex. The basic phases of the coating composition are molybdenum oxides $\left(\mathrm{MoO}_{3}, \mathrm{MoO}_{2}\right.$, and $\left.\mathrm{Mo}_{18} \mathrm{O}_{52}\right)$, spinel $\left(\mathrm{Fe}_{3} \mathrm{O}_{4}\right)$, 
and cobalt, nickel, and iron molybdates $\left(\mathrm{CoMoO}_{4}, \mathrm{NiMoO}_{4}\right.$, and $\left.\mathrm{FeMoO}_{4}\right)$. Molybdenum oxide $\mathrm{MoO}_{3}$ has a stable layered structure, consisting of $2 \mathrm{D}$ networks bound by vertices of $\left[\mathrm{MoO}_{6}\right]$ octahedral. The weak binding between layers in the structure of a rhombic $\mathrm{MoO}_{3}$ enables these layers to be rearranged into polymorphic modifications of $\mathrm{MonO}_{3 n-x}$ by the crystallographic shear mechanism [184]. This accounts for the presence of $\mathrm{Mo}_{18} \mathrm{O}_{52}$ in the coating's substance.

The transmission electron microscopic data demonstrated that the electron diffraction patterns apart from the a.m. phases contain lines of molybdenum oxide $\mathrm{Mo}_{4} \mathrm{O}_{11}$ and complex oxides $\mathrm{CoFe}_{2} \mathrm{O}_{4}$ and $(\mathrm{Co}, \mathrm{Ni}) \mathrm{Fe} \mathrm{O}_{2} \mathrm{O}_{4}$ with an inverted spinel structure. The oxides $\mathrm{Mo}_{18} \mathrm{O}_{52}$ and $\mathrm{MoO}_{3}$ are the most active catalytic phases of a composite coating with high selectivity that were obtained in [182].

Compared with the interplanar spacings $\left({ }^{\circ}\right)$ of the known molybdenum oxides [185], the whole set of interplanar spacings obtained using X-ray and HRTEM data suggests that the coating substance contains $\mathrm{MoO}_{2}$ (space group $\mathrm{P} 21 / n), \mathrm{Mo}_{4} \mathrm{O}_{11}$ (space group $\mathrm{P}_{n m a}$ ), and $\beta-\mathrm{MoO}_{3}$ (space group $\mathrm{P} 21 / c$ ). The electron-microscopic study of oxide compounds obtained demonstrated that these compounds are present in coating composition in the form of agglomerates of particles (Fig. 4a) having a needle morphology (Fig. 4b). The coating itself has a cracked microstructure that is characteristic of oxygen compounds of molybdenum [186]. The calculation of coating crystalline particle sizes using Debye-Scherrer formula showed that their sizes range from $6.5-9 \mathrm{~nm}$
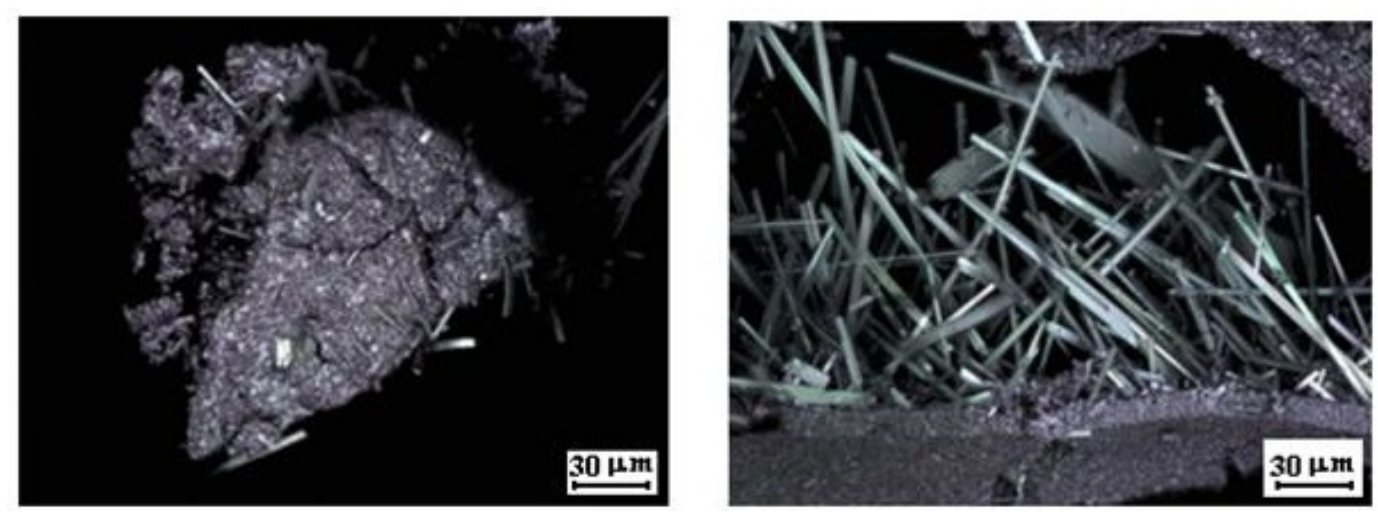

FIG. 4. Micrographs of the composite coatings substance. (a) Agglomerates of oxide compounds and (b) structure of separate particles

The oxides $\mathrm{MoO}_{2}, \mathrm{MoO}_{3}, \mathrm{Mo}_{4} \mathrm{O}_{11}, \mathrm{Mo}_{18} \mathrm{O}_{52}, \mathrm{Fe}_{3} \mathrm{O}_{4}, \mathrm{CoFe}_{2} \mathrm{O}_{4},(\mathrm{Co}, \mathrm{Ni}) \mathrm{Fe}_{2} \mathrm{O}_{4}, \mathrm{CoMoO}_{4}, \mathrm{NiMoO}_{4}, \mathrm{FeMoO}_{4}$ that are present in composite coatings represent themselves as heterogeneous catalysts which are used in oxidation processes as cathode materials for chemical power sources and increase the protective ability in corrosive environments [187-189].

Composite oxide materials developed in [179-182] were investigated for their potential use as catalysts in liquid-phase oxidations of glyoxal to glyoxylic acid. The test results showed that their catalytic activity is greater than that of Pt- and Pd-containing catalysts: the conversion value is higher by $13 \%$, and the selectivity value by $20 \%$. Composite coatings based on transition metal oxides not only have good catalytic properties, but good performance characteristics as well. Corrosion-protective properties increase by 25 - to 50 -fold when the coating thickness is 15 microns, tensile strength is $3.1 \mathrm{MPa}$ and microhardness is $250 \mathrm{MPa}$.

The real advantage of the above research is the fact that for the first time, composite coatings based on molybdenum oxides, complex molybdenum oxides and its oxygen compounds with iron group metals were obtained on a solid substrate by deposition of their salts from aqueous solutions using transient electrolysis.

\section{Conclusion}

In this review, the principles for the formation of oxide composite nanostructured materials by electrochemical methods are considered and the benefits of transient electrolysis when obtaining such materials are shown. The use of an asymmetric alternating current allows one to obtain principally new oxide nanostructured composite materials both based on metal substrate oxidation processes and metal oxides deposition from aqueous solutions of their salts. The use of an asymmetric alternating current allows the creation of principally new oxide nanostructured composite materials both based on metal substrate oxidation processes and metal oxides deposition from aqueous solutions of their salts. This approach expands the spectrum and methods of new nanostructured materials considerably [190, 191]. 
The development of technologies to produce oxide composite nanostructured materials by a method of transient electrolysis is one of the promising directions for nanotechnologies because of its such obvious advantages, such as availability, simplicity of experimental design, relative low costs. Nanomaterials obtained by this method can be very promising as optically selective coatings used in helioplants and as catalytically active materials in oxidation processes, cathode materials in chemical current sources, sensors for monitoring the gas content in the atmosphere, and can significantly increase corrosion resistance and protective ability in a number of corrosive environments. The method of transient electrolysis enables one to obtain composite materials based on complex oxides of molybdenum, cobalt, manganese, nickel, iron, vanadium as disordered solid solutions with a defective structure. The latter determines a large set of their various properties.

Due to the cycling processes on the surface of the substrate (steel, nickel, copper and other metals) a transition spinel layer is formed which ensures high adhesion of the obtained composite oxide material. The deposition of oxides from aqueous solutions of their salts inder electrolysis by an asymmetric alternating current, as is shown in the reviewed works, occurs when an average cathodic current is more than anodic one, the electrode periodically being an anode or a cathode. The deposited composite oxide coatings are still not adequately investigated. The use of an asymmetric alternating current can lead to new, exciting and unexpected results which, undoubtedly, will find many new applications.

\section{Acknowledgements}

We thank Professor V. V. Gusarov, doctor of chemical sciences, for valuable advice in discussion of the experimental results.

\section{References}

[1] Raeva O.V., Shestakov I.Ya. Electrochemical Method of Discharged Waters Cleaning with of Alternating Curent. Journal of Siberain University. Engeneering \& Technologies, 2011, 3 (4), P. 348-355.

[2] Kilimnik A.B., Nikiforova E.Y. Electrochemical behavior of nickel and its oxides in concentrated sodium hydroxide solutions. Russian Journal of Electrochemistry, 2013, 49 (12), P. 1122-1126.

[3] Degtyareva E.E., Kilimnik A.B., Ankudimova I.A. Anodic Oxidation of Sodium 2-mercaptobenztiazolate anion in the Presence of 5-Methyl-2- hexanol. Russian Journal of Electrochemistry, 2007, 43 (10), P. 1203-1205.

[4] Klochko N.P., Volkova N.D., Starikov V.V. et al. Utilization of alternating current methods for manufacture of selective absorbing coatings for heat collectors. Functional Materials, 2005, 12 (3), P. 123-125.

[5] Zhang J., Ge H., Li Z., Ding Z. Internal heating of lithium-ion batteries using alternating current based on the heat generation model in frequency domain. Journal of Power Sources, 2015, 273, P. 1030-1037.

[6] Abdulla T., Yerokhin A., Goodall R. Effect of plasma electrolytic oxidation coating of the specific strength. Materials and design, 2011, 32, P. 3742-3749.

[7] Yoshioka T., Chavez-Valdez A., Rocther J.A. et al. AC electrophoretic deposition of organic-inorganic composite coatings. Journal of colloid and interface science, 2013, 392, P. 167-171.

[8] Kudryavtsev Yu.D., Bespalova Zh.I., Pyaterko I.A. et al. Optimization of anodic aluminum oxide filling with polytetrafluoroethylene in polarization with asymmetrical alternating current. Russian Journal of Applied Chemistry, 2000, 73 (4), P. 631-634.

[9] Makarochkina S.M., Rozin Yu.I., Samarin K.M. et al. Electrochemical Synthesis of Tetraethylleaf at a Lead Trickle-Bed Electrode. Soviet Electrochemistry, 1985, 21 (12), P. 1529-1533.

[10] Alsrayhen E., McLeod E. et al. Impact of AC/DC spark anodizing on the corrosion resistance of Al-Cu alloys. Electrochimica Acta, 2011, 56, P. 6041-6048.

[11] Chávez-Valdez A., Boccaccini A.R. Innovations in electrophoretic deposition: Alternating current and pulsed direct current methods. Electrochimica Acta, 2012, 65, P. 70-89.

[12] Chávez-Valdez A., Herrmann M., Boccaccini A.R. Alternating current electrophoretic deposition (EDP) of TiO 2 nanoparticles in aqueous suspensions. Journal of Colloid and Interface Science, 2012, 375, P. 102-105.

[13] Hibino T., Inoue T., Sano M. Electrochemical reduction of NO by alternating current electrolysis using yttria-stabilized zirconia as the solid electrolyte: Part II. Modification of Pd electrode by coating with Rh. Solid State Ionics, 2000, 130 (1-2), P. 31-39.

[14] Klochko N.P., Volkova N.D., Starikov V.V. et al. Utilization of alternating current methods for manufacture of selective absorbing coatings for heat collectors. Functional Materials, 2005, 12 (3), P. 548-554.

[15] Hekman F., Sohrabi B., Rahmanifar M.S. Growth of the cobalt using AC electrochemical deposition on anodized aluminum oxide templates. J. Nanostruct. Chem., 2014, http://link.springer.com/ article/10.1007/s40097-014-0105-2.

[16] Karimi E.Z., Esmaeilzaden J., Marzbanrad E. Electrospun $\mathrm{TiO}_{2}$ nanofibre-based gas sensors fabricated by AC electrophoresis deposition. Bull. Mater. Sci., 2015, 38 (10), P. 209-214.

[17] Sadykov N.R., Kocherga E.Y., Dyachkov P.N. Nonlinear current in modified nanotubes with exposure to alternating and cocstant electric fields. Russian Journal of Inorganic Chemistry, 2013, 58 (8), P. 951-955.

[18] Therese G.H.A., Kamath P.V. Electrochemical Synthesis of Metal Oxides and Hydroxides. Chem. Mater., 2000,12 (5), P. $1195-1204$.

[19] Korobochkin V.V., Balmashov M.A., Gorlushko D.A. et al. Phase Composition and Pore Structure of Nanoparticulate Tin Oxides Prepared by AC Electrochemical Synthesis. Inorganic Materials, 2013, 49 (10), P. 993-999.

[20] Korobochkin V.V., Kosintsev V.I., Bystritskii L.D., Kovalevskii E.P. Preparation of Aluminum Hydroxide Gel by AC Electrolysis. Inorganic Materials, 2002, 38 (9), P. 914-916. 
[21] Usoltseva N.V., Korobochkin V.V., Balmashnov M.A. Air Carbonisation of AC Electrochemical Copper and Aluminium Oxidation Products. International Journal of Engeneering \& Technology, 2013, 2 (1), P. 2355-2362.

[22] Dolinina A.S., Korobochkin V.V., Usoltseva N.V. et al. Joint destruction of cadmium and copper at alternating current electrolysis in sodium hydroxide solution. Procedia Chemistry, 2014, 10, P. 369-372.

[23] Raju K., Yoon D.H. Electrophoretic deposition of $\mathrm{BaTiO}_{3}$ in an aqueous suspension using asymmetric alternating current. Materials Letters, 2013, 110, P. 188-190.

[24] Jagminas A., Valsiūnas I., Šimkūnaitė B., Vaitkus R. Pecularities of $\mathrm{Bi}^{0}$ nanowire arrays growth within the alumina template pores by ac electrolysis. Journal of Crystal Growth, 2008, 310, P. 4351-4357.

[25] Sankar P.R., Tiwari P., Kumar R. et al. Synthesis and characterization of cadmium selenide nanostructures on porous aluminum oxide templates by frequency alternating current electrolysis. Applied Surface Science, 2010, 256, P. 2097-2103.

[26] Atrashchenko A.V., Krasilin A.A., et al. Electrochemical methods of synthesis of hyperbolic metamaterials. Nanosystems: Physics, Chemistry, Mathematics, 2012, 3 (3), P. 31-51.

[27] Yoon C., Suh J.S. Electrochemical Fabrication of CdS/Co Nanowire Arrays in Porous Aluminum Oxide Templates. Bull. Korean Chem., 2002, 23 (11), P. 1519-1523.

[28] Sameshima T., Hirata Y. et al. Factors affecting formation of ceria nanoparticles by alternating current electrolysis of aqueous solutions. Materials Chemistry and Physics, 2012, 136, P. 313-316.

[29] Xu J. Synergy effect on a suspended mixture of ceria and activated carbon for the photocatalytic degradation of phenol. Powder Tech., 2011, 210, P. 1-5

[30] Wang C., Ao Y., et al. Preparation, characterization and photocatalytic activity of a novel composite photocatalyst: Ceria-coated activated carbon. Journal of Hazardous Materials, 2010, 184 (1-3), P. 35-41.

[31] Kang H.S., Kang Y.C., Koo H.Y. et al. Nano-sized ceria particles prepared by spray pyrolysis using polymeric precursor solutio. Mater. Sci. Eng. B, 2006, 127 (2-3), P. 99-104.

[32] Wang Y., Zhang F., Guo Y. et al. 3D navicular ceria micro/nanocomposite structure with multi-layered arrangement and its application in CO oxidation. Mater. Chem. Phys., 2010, 120 (1), P. 23-30.

[33] Ivanov V.K., Kopitsa G.P., et al. Hydrothermal growth of ceria nanoparticles. Russian Journal of Inorganic Chemistry, 2009,54 (12), P. $1857-1861$.

[34] Ivanov V.K., Polezhaeva O.S., et al. Hydrothermal microwave synthesis of nanocrystalline cerium dioxide. Doklady Chemistry, 2009, 426 (2), P. 131-133.

[35] Panahi-Kalamuei M., Alizadeh S., Mousavi-Kamazani M., Salavati-Niasari M. Synthesis and characterization of CeO ${ }_{2}$ nanoparticles via hydrothermal route. Journal of Industrial and Engineering Chemistry, 2015, 21, P. 1301-1305.

[36] Rao R., Yang M., et al. Mesoporous $\mathrm{CeO}_{2}$ nanobelts synthesized by a facile hydrothermal route via controlling cationic type and concentration of alkali. Microporous and Mesoporous Materials, 2013, 169, P. 81-87.

[37] Pinjari D.V., Pandit A.B. Room temperature synthesis of crystalline $\mathrm{CeO}_{2}$ nanopowder: Advantage of sonochemical method over conventional method. Ultrason. Sonochem., 2011, 18 (5), P. 1118-1123.

[38] Baranchikov A. Y., Ivanov V.K., Tretyakov Yu. D. Sonochemical synthesis of inorganic materials. Russian Chemical Reviews, 2007, 76 (2), P. 133.

[39] Yin L., Wang Y., Pang G. et al. Sonochemical synthesis of cerium oxide nanoparticles-effect of additives and quantum size effect. J. Colloid and Interface Sci., 2002, 246, P. 78-84.

[40] Ishutina Z.N., Gusarov V.V., Malkov A.A. et al. Phase Transformations in Nanosized $\gamma-\mathrm{Al}_{2} \mathrm{O}_{3}-\mathrm{SiO}_{2}-\mathrm{TiO}_{2}$. Zhurnal Neorganicheskoj Khimii, 1999, 44 (1), P. 16-19.

[41] Vasilevskaya A., Almjasheva O. Features of phase formation in the $\mathrm{ZrO}_{2}-\mathrm{TiO}_{2}$ system under hydrothermal conditions. Nanosystems: physics chemistry mathematics, 2012, 3 (4), P. 75-78.

[42] Baranchikov A.E., Ivanov V.K., Tretyakov Yu.D. Hydrothermal microwave synthesis of nanocrystalline anatase. Doklady Chemistry, 2012, 447 (1), P. 241-243.

[43] Leyva-Porras C., Toxqui-Teran A., et al. Low-temperature synthesis and characterization of anatase $\mathrm{TiO}_{2}$ nanoparticles by an acid assisted solgel method. Journal of Alloys and Compounds, 2015, 647, P. 627-636.

[44] Ouzzine M., Maciá-Agulló J.A., et al. Synthesis of high surface area $\mathrm{TiO}_{2}$ nanoparticles by mild acid treatment with $\mathrm{HCl}$ or $\mathrm{HI}$ for photocatalytic propene oxidation. Applied Catalysis B: Environmental, 2014, 154-155, P. 285-293.

[45] Prakash T., Navaneethan M., et al. Synthesis of TiO2 nanoparticles with mesoporous spherical morphology by a wet chemical method. Materials Letters, 2012, 82, P. 208-210.

[46] Kosobudsky I.D., Ushakov N.M., Yurkov G. Yu. Et al. Synthesis and Structure of Polyethylene-Matrix Composites Containing Zinc Oxide Nanoparticles. Inorganic Materials, 2005, 41 (11), P. 1172-1177.

[47] Bugrov A.N., Vlasova E.N., et al. Distribution of zirconia nanoparticles in the matrix of poly(4,4'-oxydiphenylenepyromellitimide). Polymer Science Series B, 2012, 54 (9-10), P. 486-495.

[48] Yudin V.E., Otaigbe J.U., et al. Effects of nanofiller morphology and aspect ratio on the rheo-mechanical properties of polimide nanocomposites. Express Polymer Letters, 2008, 2 (7), P. 485-493.

[49] Kononova S.V., Korytkova E.N., et al. Nanocomposite based on polyamidoimide with hydrosilicate nanoparticles of varied morphology. Russian Journal of Applied Chemistry, 2007, 80 (12), P. 2142-2148.

[50] Kononova S.V., Korytkova E.N., Maslennikova T.P. et al. Polymer-Inorganic Nanocomposites Based on Aromatic Polyamidoimides Effective in the Processes of Liquids Separation. Russian Journal of General Chemistry, 2010, 80 (6), P. 1136-1142.

[51] Gofman I.V., Svetlichnyi V.M., Yudin V.E. et al. Modification of Films of Heat-Resistant Polyimides by Adding Hydrosilicate and Carbon Nanoparticles of Various Geometries. Russian Journal of General Chemistry, 2007, 77 (7), P. 1158-1163.

[52] Golubeva O.Yu., Yudin V.E., et al. Nanocomposites on the basis of polyimide termoplasts and magnesium-silicate nanoparticles with montmorillonite structure. Russian Journal of Applied Chemistry, 2007, 80 (1), P. 106-110.

[53] Ivanov V.K., Shaporev A.S., et al. Synthesis of polymer composites based on nanocrystalline $\mathrm{ZnO}_{\text {and }} \mathrm{CeO}_{2}$. Doklady Chemistry, 2010, 431 (2), P. 109-112. 
[54] Gorelik V.S., Mikov S.V., Sokolovskii M.I., Tsuzuki T. Secondary Emission of Nanocrystalline Zinc Oxide. Inorganic Materials, 2006, 42 (3), P. 282-285.

[55] Ezhovskii Yu. K., Egorov A.L. Chromium Oxide Nanolayers on Gallium Arsenide. Inorganic Materials, 2006, 42 (4), P. $368-373$.

[56] Yue H.M., Liu Z.L., Wang Y., Yao K.L. Electrical Properties of Nanocrystalline $\mathrm{CeO}_{2}-\mathrm{Y}_{2} \mathrm{O}_{3}$ Thin Films Prepared by the Sol-Gel Method. Inorganic Materials, 2003, 39 (7), P. 720-724.

[57] Almjasheva O.V., Korytkova E.N., Maslov A.V., Gusarov V.V. Preparation of nanocrystalline alumina under hydrothermal conditions. Inorganic Materials, 2005, 41 (5), P. 4604-67.

[58] Pozhidaeva O.V., Korytkova E.N., Romanov D.P., Gusarov V.V. Formation of $\mathrm{ZrO}_{2}$ nanocrystals in hydrothermal media of various chemical compositions. Russian Journal of General Chemistry, 2002, 72 (6), P. 849-853.

[59] Komlev A.A., Gusarov V.V. Mechanism of Nanocrystals Formation of the Spinel Structure in the $\mathrm{MgO}-\mathrm{Al}_{2} \mathrm{O}_{3}-\mathrm{H}_{2} \mathrm{O}$ System under the Hydrothermal Conditions. Russian Journal of General Chemistry, 2011, 81 (1), P. 2222-230.

[60] Tomkovich M.V., Andrievskaya E.R., Gusarov V.V. Formation under hydrothermal conditions and structural features of nanoparticles based on the system $\mathrm{ZrO}_{2}-\mathrm{Gd}_{2} \mathrm{O}_{3}$. Nanosystems: Physics, Chemistry, Mathematics, 2011, 2 (2), P. 6-14 (In Russian).

[61] Bugrov A.N., Almjasheva O.V. Formation of nanoparticles Cr2O3 in hydrothermal conditions. Nanosystems: Physics, Chemistry, Mathematics, 2011, 2 (4), P. 126-132 (In Russian).

[62] Gusarov V.V., Ishutina Zh.N., Malkov A.A., Malygin A.A. Peculiarities of the solid-phase chemical reaction in formation of mullite in the nanosize film composition. Dokl. Akad. Nauk, 1997, 357 (2), P. 203-205 (In Russian).

[63] Gusarov V.V. Fast Solid-Phase Chemical Reactions. Russian J. of Gen. Chem., 1997, 67 (12), P. 1846-1851.

[64] Kolenko Yu.V., Burukin A.A., Churagulov B.R. Hydrothermal synthesis of nanocrystalline powders of various crystalline phases of $\mathrm{ZrO}_{2}$ and $\mathrm{TiO}_{2}$. Russian Journal of Inorganic Chemistry, 2002, 47 (1), P. 1609-1615.

[65] Pourmortazavi S.M., Marashianpour Z., Karimi M.S., Mohammad-Zadeh M. Electrochemical synthesis and characterization of zinc carbonate and zinc oxide nanoparticles. Journal of Molecular Structure, 2015, 1099, P. 232-238.

[66] Harra J., Nikkanen J.-P., et al. Gas phase synthesis of encapsulated iron oxidetitanium dioxide composite nanoparticles by spray pyrolysis. Powder Technology, 2013, 243, P. 46-52.

[67] Srivastava V., Gusain D., Sharma Y.C. Synthesis, characterization and application of zinc oxide nanoparticles (n-ZnO). Ceramics International, 2013, 39 (8), P. 9803-9808.

[68] Haider M.A., Capizzi A.J., Murayama M., McIntosh S. Reverse micelle synthesis of perovskite oxide nanoparticles. Solid State Ionics, 2011,196 (1), P. 65-72.

[69] Bermejo E., Becue T., Lacour C., Quarton M. Synthesis of nanoscaled iron particles from freeze-dried precursors. Powder Technology, 1997, 94 (1), P. 29-34.

[70] Khayati G.R., Nourafkan E., Karimi G., Moradgholi J. Synthesis of cuprous oxide nanoparticles by mechanochemical oxidation of copper in high planetary energy ball mill. Advanced Powder Technology, 2013, 24 (1), P. 301-305.

[71] Bayal N., Jeevanandam P. Synthesis of $\mathrm{TiO}_{2}-\mathrm{MgO}$ mixed metal oxide nanoparticles via a sol-gel method and studies on their optical properties. Ceramics International, 2014, 40 (10), Part A, P. 15463-15477.

[72] Kudryavtsev Yu.D., Fesenko L.N. Behavior of Porous Nickel during Alternating Current Electrolysis. Sov. Electrochemistry, 1976, 12 (3), P. 344-348.

[73] Kudryavtsev Yu. D., Kukoz F.I., Fesenko L.N. Experimental Study Concerning the Current Distribution in a Porous Nickel Electrode During Polarization with Alternating Current. Sov. Electrochemistry, 1975, 11 (3), P. 352-355.

[74] Bespalova Zh. I., Ivanov V.V., Smirnitskaya I.V. Fabrication of a Titanium Anode with an Active Coating Based on Mixed Oxides of Base Metals. Russian Journal of Applied Chemistry, 2010, 83 (2), P. 242-246.

[75] Galushkin N.E., Kudryavtsev Yu.D. The Effect of External Current Frequency on Depth Distribution of the Quantity of Electricity Passed Through a Porous Electrode. Russian Journal of Electrochemistry, 1993, 29 (10), P. 1030-1032.

[76] Galushkin N.E., Yazvinskaya N.N., Galushkin D.N. Generalized Model for Self-Charge Process in Alkaline Batteries. Journal of The Electrochemical Society, 2012, 159 (8), P. 1315-1317.

[77] Galushkin N.E., Fesenko L.N. Simulating Decomposition of Hydrogen Sulfide in a Three-Dimentional Electrofilter. Russian Journal of Electrichemistry, 1997, 33 (8), P. 852-856.

[78] Method of Making Selective Coating, Patent. 2393275 Russia: MPK C 25D 11/10, F24J 2/48, Bespalova Z.I., Klushin V.A., Djachishin A.S. No. 2009130707/02, Issue No. 18, 7 p.

[79] Bespalova Zh.I., Lovpache Yu.A., Lipkin M.S. et al. Composite Coatings Based on Copper Oxides Electrodeposited from Solutions and on Polymers. Russian Journal of Applied Chemistry, 2006, 79 (7), P. 1105-1109.

[80] Erokhin A.L., Lubimov V.V., Ashitkov R.V. Model of Oxide Coatings Formation During Plasma-Electrolytic Oxidizing of Aluminum in Silicate Solutions. Physics and Chemistry of Materials Treatment, 1996, 5, P. 39-44.

[81] Galushkin D.N., Yazvinskaya N.N., Galushkin N.E. Investigation of the process of thermal runway in nickel-cadmium accumulators. Journal of Power Sources, 2008, 177 (2), P. 610-616.

[82] Ivanova N.D., Ivanov S.V., Boldyrev E.I. et al. Thin-Film Cathode Materials Based on Chromium Oxides. Russian Journal of Applied Chemistry, 2003, 76 (7), P. 1067-1069.

[83] Lukiyanchuk I.V., Rudnev V.S., Panin E.S. et al. Modification with Manganese of Anodic Layers Containing Tungsten Oxides. Russian Journal of Applied Chemistry, 2003, 76 (10), P. 1597-1599.

[84] Legagneur V., Liao J.-H., et al. $\mathrm{Li}_{2} \mathrm{Mn}\left(\mathrm{VO}_{3}\right)_{4} \cdot 2 \mathrm{H}_{2} \mathrm{O}$ : synthesis, crystal structure, thermal behavior and lithium insertion/deinsertion properties. Solid State Ionics, 2000, 133, P. 161-170.

[85] Apostolova R.D., Shembel E.M., Nagirnyi V.M. Synthesis and Investigations of Electrolytic Sodium-Vanadium Oxide Compounds for Cathodes of Lithium Batteries: The Production of Compounds with Stable Initial Characteristics. Russian Journal of Electrochemistry, 2000,36 (1), P. 36-42.

[86] Nagirnyi V.M., Apostolova R.D., Baskevich A.S., Shembel E.M. Joint Electrolytic Deposition of Vanadium (V) and Chromium (III) Oxides from Aqueous Sulfate Solutios. Russian Journal of Applied Chemistry, 2004, 77 (11), P. 1777-1780.

[87] Shembel E.M., Apostolova R.D., Nagirny V.M. Electrochemical Synthesis of the Cathode Materials Based on Metal Oxides for Lithium Secondary Batteries. The 197th Meeting of the Electrochemical Society: Abstracts of Papers, 2000, Toronto, P. 105. 
[88] Nagirnyi V.M., Apostolova R.D., et al. Joint Electrolytic Deposition of Vanadium and Manganese Oxides. Russian Journal of Applied Chemistry, 2002, 75 (4), P. 552-557.

[89] Zoski C.G. Handbook of Electrochemistry. Elsevier, 2007, 934 p.

[90] Apostolova R.D., Kolomoets O.V., Danilov M.O., Shembel E.M. Electrolytic Co, Ni-Bimetalsulfide Composites with Hydrophilizated Multi-Wall Carbon Nanotubes in a Prototype Lithium Accumulator. Surface Engineering and Applied Electrochemistry, 2014, 50 (1), P. 18-27.

[91] Nagirnyi V.M., Apostolova R.D., et al. Electrolytic Deposition of Cobals (III) Oxide in the Presence of Nickel (II) and Chromium (III) Ions. Russian Journal of Applied Chemistry, 2002, 75 (6), P. 905-910.

[92] Nagirnyi V.M., Apostolova R.D., Baskevich A.S., Shembel E.M. Anodic Deposition of Vanadium (V) Oxide from Solutions in the Presence of Nickel Ions. Russian Journal of Applied Chemistry, 75 (12), P. 1968-1971.

[93] Nagirnyi V.M., Apostolova R.D., Shembel E.M. Electrodeposition of Molybdenum Oxide and Its Structural Characteristics. Russian Journal of Applied Chemistry, 2006, 79 (9), P. 1438-1442.

[94] Nagirnyi V.M., Apostolova R.D., Baskevich A.S. et al. Electrolytic Preparation of Vanadium (V) Oxide from Oxovanadium (IV) Sulfate Solutions in the Presence of Sodium Ions. Russian Journal of Applied Chemistry, 2001, 74 (9), P. 1470-1473.

[95] Nagirnyi V.M., Apostolova R.D., Baskevich A.S. et al. Electrolytic Preparation of Vanadium (V) Oxide from Saturated Solutions of Ammonium Metavanadate. Russian Journal of Applied Chemistry, 2001, 74 (9), P. 1474-1478.

[96] Nagirnyi V.M., Apostolova R.D., Baskevich A.S. et al. Electrolytic Synthesis of Binary Oxide Systems Based on Manganese (II) Oxide. Russian Journal of Applied Chemistry, 2002, 75 (2), P. 213-218.

[97] Nagirnyi V.M., Apostolova R.D., Baskevich A.S., Shembel E.M. Electrolytic Deposition of Molybdenum Oxide from Aqueous Solutions at Room Temperature. Russian Journal of Applied Chemistry, 2004, 77 (1), P. 71-73.

[98] Nagirnyi V.M., Apostolova R.D., Shembel E.M. Surface Morphology of Electrolytic Deposits of Vanadium, Cobalt, and Manganese Oxides. Russian Journal of Applied Chemistry, 2006, 79 (9), P. 1443-1446.

[99] Belous A.G., Yanchevskii O.Z., Kramarenko A.V. Synthesis of Nanosize Particles of Cobalt and Nickel Oxides from Solutions. Russian Journal of Applied Chemistry, 2006, 79 (3), P. 345-350.

[100] Poizot P., Laruelle S., et al. Nano-sized transition-metal oxides as negative-electrode materials for lithium-ion batteries. Nature, 2000, 407, P. 496-499.

[101] Nuli Y.N., Zhao S.L., Qin Q.Z. Nanocrystalline tin oxides and nickel oxide film anodes for Li-ion batteries. J. Power Sources, 2003, 14, P. 113-120.

[102] Ahmad A.S., El-Shobaky G.A., Al-Noaimi A.N., El-Shobaky H.G. Surface and catalytic properties of gamma-irradiated CuO and NiO catalysts. Mater. Lett., 1996, 26, P. 107-112.

[103] Curri M.L., Agostiano A., Mavelli F. et al. Reverse micellar systems: self organized assembly as effective route for the synthesis of semiconductor nanocrystals. Mater. Sci. Eng. C. Biomim. Mater., Sens. Syst., 2002, 22, P. 423-426.

[104] Dirksen J.A., Duval K., Ring T.A. NiO thin-film formaldehyde gas sensor. Sensors and Actuators B: Chemical, $2001, \mathbf{8 0}$ (2), P. 106-115.

[105] Hotový, I., Huran J., et al. Preparation and characterization of NiO thin films for gas sensor applications. Vacuum, 2000,58 , P. 300-307.

[106] Svegl F., Orel B., Hutchins M.G. et al. Structural and spectroelectrochemical investigations of sol-gel derived electrochromic spinel Co3O4 films. J. Electrochem. Soc., 1996, 143, P. 1532-1539.

[107] Takanashi T. First-principles Investigation of the Phase Stability for $\mathrm{Ba} . \mathrm{Ba}\left(\mathrm{B}_{1 / 3}^{\prime 2+} \mathrm{B}_{2 / 3}^{\prime \prime} 5+\right) \mathrm{O}_{3}$ Microwave Dielectrics with the Complex Perovskite Structure. Jpn. J. Appl. Phys., 2000, 39, P. 5637-5641.

[108] Nagirnyi V.M., Apostolova R.D., Shembel E.M. Anodic Processes Occurring upon V2O5 Electrodeposition. Russian Journal of Applied Chemistry, 2007, 80 (1), P. 71-73.

[109] Stepanova L.I., Ivashkevich L.S., Branitskii G.A. Hydrothermal Synthesis of Tungsten Molybdenum Mixed Oxides. Russian Journal of Inorganic Chemistry, 2009, 54 (10), P. 1553-1558.

[110] Švachula J., Tichy J., Machek J. Oxidation of Propanal on Molybdenum-Vanadium Oxide Catalyst. Catalysis Letters, 1989 , 3, P. $257-262$.

[111] Neiman A.Ya., Trafieva M.F., Kostikov Yu.P. Chemism and mass-transfer routes during phase formation in the $\mathrm{V}_{2} \mathrm{O}_{5}-\mathrm{MoO}_{3}$. Russian Journal of Inorganic Chemistry, 2005, 50 (10), P. 1472-1484.

[112] Sviridova T.V., Antonova A.A., Kokorin A.I. et al. Nanostructured Vanadium - Molybdenum Mixed Oxides Prepared by the Solvothermal Method. Russian Journal of Physical Chemistry, 2015, 9 (1), P. 22-28.

[113] Shagisultanova G.A., Ardasheva L.P., Orlova I.A. Electro- and Photoelectroactivity of Thin-Layer Polymars Based on [NiSalen] and [NiSalphen] Complexes. Russian Journal of Applied Chemistry, 2003, 76 (10), P. 1631-1636.

[114] Mikhailov O.V. Immobilization of (dd)heteronuclear hexacyanoferrates (II) in a gelatin matrix. Russian Chemical Bulletin, 2008, 57 (1), P. $8-17$.

[115] Airapetyan S.S., Balayan G.G., Khachatryan A.G. Synthesis and Some Characteristics of Magnetic Matrices for Fixation of Biologically Active Substances. Russian Journal of Applied Chemistry, 2001, 74 (3), P. 519-521.

[116] Pimkov I.V., Lutsenko O.G., Golubchikov O.A. Immobilization of Cobalt Disulfophthalocyanine Complex on Polypropylene. Russian Journal of Applied Chemistry, 2007, 80 (5), P. 828-832.

[117] Electroplating solution composition for organic polymer-zinc alloy composite plating and plated metal material using such composition. Patent EP 1719826 A1, MPK C 25D 5/26, C 25 D 15/02, C 25 D 3/56, Haruta Y., Hiraki T., Kubota K., N 04801689.3, 2006/45, 14 p.

[118] Polymer coated particles having immobilized metal ions on the surfaces thereof. Patent 4677027 A US: MPK 32 B 15/08, B 32 B 19/02; B 32 B 19/04, Lindahl M., Porath J. N 06/786,857, N 788,857, 5 p.

[119] Process for the surface-immobilization of anti-microbial polymers by metal deposition. Patent 0144657 US: MPK 25 D 9/02, C 25 D 205/316, Inhester M., Ottersbach P. N 10/645,553.

[120] Pomogailo A.D. Catalysis by polymer - immobilized metal complexes. Gordon \& Breach Science Publishing. Amsterdam, 1998,322 p.

[121] Tarnizhevskij B.V. Assessment of the Effectiveness of Operating Solar Heating Installation in Russia. Thermal Engineering, 1996, 43 (5), P. 373-376.

[122] Multilaer Selective Absorbing Coating for Solar Collector and Method of Making Said Coating. Patent 2407958 Russia: MPK F 24 J 2/48, Djachishin A.S., Jazvina I.M., Stadnik A.V. N 2008149287/06. 
[123] Alturaif H.A., ALOthman Z.A., Shapter J.G., Wabaidur S.M. Use of Carbon Nanotubes (CNTs) with Polymers in Solar Cells. Molecules, 2014 (http://www.mdpi.com/journal/molecules).

[124] Multi-layer selective coating for solar collector. Patent 93028687 Russia: MPK F 24J2/02, Dyachshin A.S., Dremlyuga A.A., Saksonsky V.A., 93028687/06, Bull. No. 10.

[125] Multi-Layer Selective Coating For Solar Collector. Patent 2044964 Russia: P6 F24J2/48, Dyachshin A.S., Dremlyuga A.A., Saksonsky V.A. N 93028687/06, Bull. No. 15

[126] Absorbing Coating. Patent 2271058 Russia: P H01Q17/00, Golovkov A.A., Verbitskij A.V. N 2004122349.09, Bull. No. 6.

[127] Absorbing Coating For Attenuation of Reflected Electromagnetic Waves; Capacitance Element For Absorbing Coating; Inductance Element For Absorbing Coating. Patent 2125327 Russia: 6 H01Q17/00, Marushkin V.A. N 96102682/09, Bull. No. 8.

[128] Absorbermaterial für solarthermische Anwendung Gew. 202006011147 U1 DE, F24J2/48, NARVA Lichtquellen GmbH + Co. KG, 09618 Brand-Erbisdorf, N 202006011147U1; filed Sep.21.2006, date of patent Oct.26.2006.

[129] Moldovanov K.A., Hecceck R., Skrynnikov A.M. Reflectivities of Light-Absorptive coatings Within Visible Wavelenghts Range. Proceedung of SPIE, 2000, 4093, P. 181-192.

[130] Fredj N., Burleigh T.D. Transpassive Dissolution of Copper and Rapid Formation of Brilliant Colored Oxide Films. Journal of Electrochemical Society, 2011, 158 (4), P. 104-110.

[131] Moldovanov K.A., Anisimova I.A., Skrynnikov A.M. Reflectivity of Al coating sputtered by using the nitrogencontaining plasma. Proceeding of SPIE, 2001, 4447, P. 98-108.

[132] Pigments Reflecting Optical Emission with Specified Long-Wave Border and Absorbing Emission with Specified Short-Wave Border or at Specified Wavelength. Patent 2127747 Russia: P6 C09C1/00, C09D5/32, C09D5/33Egorov Ju. P., Malinovskaja T.D. N 95110119/04, Bull. No. 9.

[133] Singh S.M. Paints and Painting Procedures for Solar Energy Collectors. Proceedings of "the Workshop on Solar Water Heating Systems", 1985, New Delhi, India, 6-10 May, P. 153-158.

[134] ISO/CD 12592,2 Solar Energy-Materials for Flat-Plate Collectors. Qualification Test Procedure for Solar Surface Durability.

[135] Mozalev A., Surganov A., Magaino S. Anodic Process for Forming Nanostructured Metal-Oxide Coatings for Large-Value Precise Microfilm Resistor Fabrication. Electrochimica Acta, 1999, 44 (21-22), P. 2891-3898.

[136] Skoneczny W., Bara M. Aluminium Oxide Composite Layers Obtained by the Electrochemical Method in the Presence of Graphite. Material Science - Poland, 2007, 25 (4), P. 1053-1062.

[137] Stojanov E., Popov D., Stoychev D. Bildung und Schutzwirkung von Oxidschichten and of Aluminum. Galvanotechnik, 1994, 85 (10), P. 3240-3247.

[138] Yang S., Aoki Y., Skeldon P. et al. Growth of porous anodic alumina films in hot phosphate-glycerol electrolyte. J. Solid State Electrochem., 2011, 15, P. 689-696.

[139] Patermarakis G., Moussoutzanis K. Aluminium anodizing in ultra-dense sulfate baths: discovery by overall kinetic and potentiometric studies of the critical role of interface colloidal $\mathrm{Al}_{2}\left(\mathrm{SO}_{4}\right)_{3}$ nanoparticles in the mechanism of growth and nanostructure of porous oxide coatings. J. Solid State Electrochem., 2005, 9, P. 205-233.

[140] Koyama S., Aoki Y., Nagata S., Habazaki H. Formation and dielectric properties of anodic oxide films on Zr-Al alloys. J. Solid State Electrochem., 2011, 15, P. 2221-2229.

[141] Henley V.F. Anodic Oxidation of Aluminium and Its Alloys. Pergamon Press, Oxford, 1982, 170 p.

[142] Dolgovesova I.P., Bakovets V.V., Nikiforova G.L., Royak A.Ya. Distribution of Alloying Components During The Anodic-Spark Oxidation of Aluminum Alloys in Concentrated Sulfuric Acid. Protection of Metals, 1987, 23 (4), P. 515-518.

[143] Korolev Y.A., Greish A.A., Kozlova L.M. et al. Glycerol Dehydroxylation in Hydrogen on a Raney Cobalt Catalyst. Catalysis in Industry, 2010, 2 (3), P. 287-289.

[144] Gnedenkov S.V., Khrisanfova O.A., Ignateva L.N. et al. Aluminum Complexation with Metal Tartrates. Russian Journal of Inorganic Chemistry, 2005, 50 (12), P. 1925-1932.

[145] Clark A. Oxides of the Transition Metals as Catalysts. Ind. Eng. Chem., 1953, 45 (7), P. 1476-1480.

[146] Temperoni G., Gignini P., Icovi M., Panero S. Non-stoichiometric molybdenum oxides as cathodes for lithium cells: Part III. cells based on $\mathrm{Mo}_{18} \mathrm{O}_{52}$. J. Electroanal. Chem., 1980, 108 (2), P. 169-180.

[147] Li Y.B., Bando Y., Golberg D., Kurasima K. Field emission from $\mathrm{MoO}_{3}$ nanobelts. Appl. Phys. Lett., 2002, 81, P. $5048-5052$.

[148] Ressler T., Walter A., Huang Z.D., Bensch W. Structure and properties of a supported $\mathrm{MoO}_{3} \mathrm{SBA}-15$ catalyst for selective oxidation of propene. Journal of catalysis, 2008, 254 (2), P. 170-179.

[149] Gervasini A., Wahba L., Finol M.D., Lamonier J.-F. Property and activity of molybdates dispersed on silica obtained from various synthetic procedures. Materials Sciences and Applications, 2012, 3, P. 195-212.

[150] Wang G., Ji Y., et al. Synthesis of molybdenum oxide nanoplatelets during crystallization of the precursor gel from its hybrid nanocomposites. Chem. Mater., 2007, 19, P. 979-981.

[151] Prasada A.K., Kubinskin D.J., Gouma P.I. Comparison of sol-gel and ion beam deposited $\mathrm{MoO}_{3}$ thin film gas sensors for selective ammonia detection. Sensors and Actuators B, 2003, 93, P. 25-30.

[152] Ivanovskaya M.I., Gurlo A. Ch., Lutynskaya E.V., Romanovskaya V.V. Effect of Heat Tretment Conditions on Formation of Paramagnitic Centers of Molybdenum in $\mathrm{MoO}_{3}$. Russian Journal of General Chemistry, 1997, 67 (11), P. 1683-1688.

[153] Ivanova N.D., Boldyrev E.I., Stadnic O.A., Zheleznova L.I. Composition and Catalytic Properties of Co (II) Anodic Oxidation Products. Ukrainskij Khimicheskij Zhurnal, 2004, 70 (5-6), P. 51-53.

[154] Tysyachny V.P., Shembel E.M., Apostolova R.D. et al. Chronovoltammetry of Electrolytic Molybdenum Oxides at the Electrochemical Intercalation/Deintercalation of Lithium Ions. J. Solid State Electrochem., 2003, 8 (1), P. $20-22$.

[155] Beltowska-Lehman E. Kinetic Correlations in Codeposition of Coatings of Molybdenum-Iron Metal Alloys. Journal of Applied Electrochemistry, 1990, 20 (1), P. 132-138.

[156] Podlaha E.J., Landolt D. Induced codeposition. I. An experimental investigation of Ni-Mo alloys. J. Electrochem. Soc., 1996, 143 (3), P. 885-892.

[157] Podlaha E.J., Landolt D. Induced codeposition. II. A mathematical model descrtibing the electrodeposition of Ni-Mo alloys. J. Electrochem. Soc., 1996, 143, P. 893-899. 
[158] Podlaha E.J., Landolt D. Induced codeposition. III. Molybdenum alloys with nickel, cobalt and iron. J. Electrochem. Soc., 1997, 144 (5), P. $1672-1680$

[159] Gomez E., Pellicer E., Valles E. Detection and characterization of molybdenum oxides formed during the initial stages of cobaltmolybdenum electrodeposition. Journal of Applied Electrochemistry, 2003, 33, P. 245-252.

[160] Gomez E., Kipervaser Z.G., Pellice E., Valles E. Extracting deposition parameters for cobalt-molybdenum alloy from potentiostatic current transients. Phys. Chem., 2004, 6, P. 1340-1344.

[161] Sabhapathi V.K., Hussain O.Md., et al. Optical absorption studies in molybdenum trioxide films. Physica status solidi (a), 1995 , 148 (1), P. 167-173.

[162] Kuznetsov V.V., Pshenichkina T.V. Kinetics of Cathodic Reactions in the Electrodeposition of Cobalt-Molybdenum Alloy. Russian Journal of Electrochemistry, 2010, 46 (4), P. 401-410.

[163] Kuznetsov V.V., Pavlov M.R., Kuznetsov K.V., Kudryavtsev V.N. Kinetics of Cathodic Processes of Deposition of Nickel-Molybdenum Alloys from an Ammonia-Citrate Electrolyte. Russian Journal of Electrochemistry, 2003, 39 (12), P. 1338-1341.

[164] Gomez E., Pellicer E., Valles E. An approach to the first stages of cobalt-nickel-molybdenum electrodeposition in sulphate-citrate medium. Journal of Electroanalytical Chemistry, 2005, 580, P. 222-230.

[165] Gomez E., Pellicer E., Valles E. Developing plating baths for the production of cobalt-molybdenum films. Surface and Coatings Technology, 2005, 197 (2-3), P. 238-246.

[166] Obradovic M.D., Stevanovic R.M., Despic A.R. Electrochemical deposition of Ni-W alloys from ammonia-citrate electrolyte. Journal of Electroanalytical Chemistry, 2003, 552, P. 185-196.

[167] McEvoy T.M., Stevenson K.J. Electrochemical quartz crystal microbalance study of the electrodeposition mechanism of molybdenum oxide thin films from peroxo-polymolybdate solution. Analytica Chimica Acta, 2003, 496 (1-2), P. 39-51.

[168] Ibrahim M.A.M., Rehim Abd El, Moussa S.O. Electrodeposition of noncrystalline cobalt-tungsten alloys from citrate electrolytes. Journal of Applied Electrochemistry, 2003, 33 (7), P. 627-633.

[169] Gomez E., Pellicer E., Valles E. Influence of the bath composition and the pH on the induced cobalt-molybdenum electrodeposition. Journal of Electroanalytical Chemistry, 2003, 556, P. 137-145.

[170] Murase K., Ando H., et al. Determination of Mo(VI) species and composition in Ni-Mo alloy plating baths by raman spectra factor analysis. J. Electrochem. Soc., 2000, 147 (6), P. 2210-2217.

[171] Nagirnyi V.M., Apostolova R.D., Shembel E.M. Electrodeposition of Molybdenum Oxide and Its Structural Characteristics. Journal of Applied Electrochemistry, 2006, 79 (9), P. 1438-1442.

[172] Nagirnyi V.M., Apostolova R.D., Baskevich A.S., Shembel E.M. Electrolytic Synthesis of Complex Oxide Systems by Cathodic Deposition of Molybdenum Oxide from Aqueous Solutions in the Presence of Nickel (II) and Thiosulfate Ions. Russian Journal of Applied Chemistry, 2003, 76 (9), P. 1438-1443.

[173] Sinkeviciute D., Baltrusaitis J., Dukstiene N. Layered molybdenum oxide thin films electrodeposited from sodium citrate electrolyte solution. J. Solid State Electrochem., 2011, 15, P. 711-723.

[174] Danilov M.O., Ivanova N.D., Boldyrev E.I. et al. Nanostructured Composites for Power Cells Based on Molybdenum-modified Carbon Nanotubes. Proceeding of Conference "11th Advanced Bateries, Accumulators and Fuel Cells, ABAF 2010”, University of Technology, Faculty of Electrical EngineringBrno, Czech Republic, 19 September 2010 through 22 September 2010, P. 39-43.

[175] Talanov V.M, Shirokov V.B. Tilting structures in spinels. Acta Cryst., 2012, A68, P. 595-606.

[176] Talanov V.M, Shirokov V.B. Atomic order in spinel structure - a group-theoretical analysis. Acta Cryst., 2014, A70, P. 49-63.

[177] Talanov V.M. Anion ordering in spinels. Physica Status Solidi (A), 1989, 115 (1), K1-K4.

[178] Talanov V.M. Calculation of structural parameters of spinels.Physica Status Solidi (B), 1981, 106 (1), P. 99-106.

[179] Bespalova Zh.I., Khramenkova A.V. Preparation of Oxide and Metal-Complex Polymer-Immobilized Composite coatings on the Steel Surface. Russian Journal of Applied Chemistry, 2012, 85 (11), P. 1681-1685.

[180] Bespalova Zh.I., Khramenkova A.V. A study of the possibility of obtaining catalytically active oxide compounds on a solid support by transient electrolysis. Russian Journal of Applied Chemistry, 2013, 86 (4), P. 539-544.

[181] Bespalova J.I., Khramenkova A.V., Abdala R.M., Dmitriev V.P. Study of the phase composition and structure of composite coatings based on transition- metal oxide compounds via X-ray diffraction and X-ray absorption fine structure spectroscop. Journal of Surface Investigation. X-ray, Synchrotron and Neutron Techniques, 2014, 8 (1), P. 60-65.

[182] Method for Obtaining Coating from Metal Oxides on Steel. Patent 2449061 Russia: P C25D 11/34, C25D 3/56, Bespalova Zh.I., Smirnitskaia I.V., Khramenkova A.V. N 2010142537/02, Bull. No. 12.

[183] Cohen E., Gutoff E. Modern Coating and Drying Technology. Wiley-VCH, 1992, 336 p.

[184] Delmon B. Catalyst Deactivation. Proceeding of the 7th International Symposium "Studies in Surface Science and Catallysis", Cancun, Mexico, 1997, p. 39.

[185] Atuchin V.V., Gavrilova T.A., Kostrovsky V.G. et al. Morphology and Structure of Hexagonal MoO 3 Nanorods. Inorganic Materials, 2008, 44 (6), P. 62-627.

[186] Majumdar S., Sharma I.G. Oxidation Behavior of $\mathrm{MoSi}_{2}$ and $\mathrm{Mo}(\mathrm{Si}, \mathrm{Al})_{2}$ Coated Mo-0.5Ti-0.1Zr-0.02C Alloy. Intermetallics, 2011, 19, P. 541-545.

[187] Tamizhmani G., Capuano G. Improved Electrocatalytic Oxygen Reduction Performance of Platinum Ternary Alloy-Oxide in SolidPolymer-Electrolyte Fuel Cells. J. Electrochem. Soc., 1994, 141 (4), P. 968-975.

[188] Kuznetsov V.V., Kalinkina A.A., Pshenichkina T.V. Electrochemical Properties of Composite Materials Based on Platinum Modified with Molybdenum Compounds. Russian Journal of Electrochemistry, 2007, 43 (7), P. 776-781.

[189] Wang Y., Fachini E.R., et al. Effect of Surface Composition of Electrochemically Codeposited Platinum/Molybdenum Oxide on Methanol Oxidation. J. Electrochem. Soc., 2001, 148, P. 222-226.

[190] Talanov, V.M., Ereyskaya, G. P. Fundamentals of Nanochemistry and Nanotechnology, edited by V.M. Talanov. Novocherkassk: SouthRussian State Polytechnical University. 2014, 524 p.

[191] Talanov V.M., Ereyskaya G.P., Yuzyuk Y.I. Introduction to Chemistry and Physics of Nanostructures and Nanostructured Materials, edited by V.M. Talanov. Moscow: Academy of Natural Science, 2008, 389 p. 